\section{Ankara Üniversitesi Eğitim Bilimleri Fakültesi Özel Eğitim Dergisi}

2021, 22(2), 395-417
ARAŞTIRMA

Gönderim Tarihi: 28.02.20

Kabul Tarihi: 27.11.20

Erken Görünüm: 17.12.20

\title{
Jest Kullanımının Görme Yetersizliğinden Etkilenmiş ve Gören Yetişkinlerin Leksikal Ulaşım Sürecine Etkisinin Karşılaştırılması*
}

\author{
Zahide Töret ${ }^{(i D)}$
}

Selda Özdemir ${ }^{\text {DD2 } 2}$

\begin{abstract}
Öz
Giriş: Jestler, leksikal ulaşım sürecinde rol oynayıcılardır. Bu araştırmanın temel amacı jestlerin GY olan ve gören yetişkinlerin leksikal ulaşım sürecine etkisini karşılaştırmaktır.

Yöntem: Araştırmanın deseni deneysel desen 2x2 tekrarlı ölçümler tasarımıdır. Araştırmaya, eğitim, cinsiyet ve yaş bakımından benzer özellikler gösteren 20 görme yetersizliği olan ve 20 gören yetişkin katılmıştır. Katılımcıların sözel performansları, Sözel Akıcılık Testi kullanılarak ölçülmüş̧ür. Leksikal ulaşım sürecinde jest kullanmanın etkisini belirlemek amacı ile katılımcılara iki gruptan oluşan hedef kelime listesinde bulunan kelimelerin anlamları okunmuştur. Katılımcıların kelimeleri jestler engellenmiş ve jestler serbest koşulunda tahmin etmeleri istenmiştir.

Bulgular: Araştırma sonunda, görme yetersizliği (GY) olan ve gören katılımcıların jest kullanmalarının serbest olduğu koşulda kullandıkları sembolik ve kendini düzenleme jestlerinin sıklıkları arasında anlamlı bir farklılık olmadığı, ancak vurgulayıcı jestleri kullanma sıklıkları arasında anlamlı farklılık olduğu sonucuna ulaşılmıştır. Jest kullanımı engellenmiş koşulda ise katılımcı grupların leksikal ulaşım süreci sonunda doğru yanıt verme sıklıkları arasında anlamlı farklılıklar olduğu görülmüştür.
\end{abstract}

Tartışma: Araştırmanın sonuçları ilgili alanyazın çerçevesinde tartışılmış, ileride yapılacak uygulama ve araştırmalar için önerilerde bulunulmuştur.

Anahtar sözcükler: Görme yetersizliği, görme yetersizliği olan yetişkinler, jestler, leksikal ulaşım, bedenlenmiş biliş teorisi.

Atıf için: Töret, Z., \& Özdemir, S. (2021). Jest kullanımının görme yetersizliğinden etkilenmiş ve gören yetişkinlerin leksikal ulaşım sürecine etkisinin karşılaştırılması. Ankara Üniversitesi Eğitim Bilimleri Fakültesi Özel Eğitim Dergisi, 22(2) 395-417. https://doi.org/10.21565/ozelegitimdergisi.696281

\footnotetext{
${ }^{*} \mathrm{Bu}$ araştırma, Zahide TÖRET tarafından Gazi Üniversitesi Eğitim Bilimleri Enstitüsü’nde tamamlanmış yüksek lisans tezinden üretilmiştir.

${ }^{1}$ Sorumlu Yazar: Arş. Gör., Gazi Üniversitesi, E-posta: zahidetoret@ gazi.edu.tr, https://orcid.org/0000-0003-2102-9876

2 Prof. Dr., Hacettepe Üniversitesi, E-posta: seldaozdemir@hacettepe.edu.tr, https://orcid.org/0000-0001-9205-5946
} 


\section{Giriş}

Jestler, konuşma ve düşünme esnasında kendiliğinden ortaya çıkan, iletişimde önemli roller üstlenen el ve kol hareketleridir (Hostetter, 2011; Kendon, 1994; McNeill, 1992). Gelişimsel olarak bakıldığında jestlerin yaşamın ilk yıllarında iletişimin ilk basamaklarında yer aldığı görülmektedir (Iverson \& Thal, 1998). Çocuklar ihtiyaçlarını belirtmede ve bildiklerini ifade etmede, işaret etme, gösterme gibi pek çok jestten yararlanmaktadırlar. İletişimin ilerlemesiyle birlikte jestler, sözel ifadeleri desteklemekte kullanılmaktadır (Goldin-Meadow \& Iverson, 2010; Goldin-Meadow \& Morford, 1985). Bununla birlikte jestlerin yalnızca iletişim amaçlı kullanılmadığ1, daha karmaşık zihinsel süreçleri düzenlemek için de kullanıldığı bilinmektedir (Kita, 2000; Melinger \& Levelt, 2004; Pine vd., 2004). Yapılan çalışmalar, beyindeki dil ve bedene ilişkin merkezlerin birbirini destekleyen ve etkileyen iki sistem olduğunu (Calvo-Merino vd., 2005; Hauk vd., 2004; Iverson \& Thelen, 1999) göstermektedir. Bu bilgiden yola çıkılarak, bireylerin kavram ediniminde yer alan görsel süreçlerinin jest kullanımını da etkileyebileceği güncel bir tartışma konusu olarak dikkat çekmektedir. (Alibali vd., 2009; Alibali vd., 2000; Pine vd., 2007).

Jestlerin ilk tanımlarında, dilin dinleyicinin kulağına, jestlerin ise dinleyicinin gözlerine hitap ettiği vurgusu dikkat çekicidir (Krauss, 1998). McNeill'e (1992) göre jestler, yalnızca el ve kolların havada hareket ettirildiği motor hareketlerden ibaret olmayan, konuşmacının fikirlerini ya da objeleri anlatırken sıklıkla doğal olarak sergilediği anlamlı el ve kol hareketleridir. Alibali (2005) ve Krauss'a (1998) göre ise jestler, konuşmay1 anlamlandırmak, motor ya da uzamsal bilgileri anlatmak için kullanılan el hareketleridir. Tanımlar farklılaşmasına rağmen jestlerin tanımlanmasında el ve kol hareketleri vurgusu ortaktır. Jestlerin el hareketleri ile sergilendiği bilinmekle birlikte, her el hareketinin jest olarak tanımlanması da mümkün değildir (Krauss vd., 1996).

Jestler zihindeki birtakım imgeleri sembolleştirme, konuşmayı yönlendirme ya da kişinin bir takım zihinsel süreçlerini düzene koyma amaçları ile kullanılan hareketlerdir (McNeill, 1992). Alanyazında yapılan çalışmalar incelendiğinde jestlerin genellikle sembolik, vurgulayıcı ve kendini düzenleme jestleri olmak üzere üçe ayrıldığı görülmektedir (Alibali, 2005). Bir nesnenin nasıl kullanıldığını, işlevini, hareketini ya da konumunu anlatabilmek için kullanılan ve semantik anlam içeren hareketler sembolik jestler (representational gestures) olarak sinıflandırılmaktadır (Alibali, 2005; Frick 1991; Krauss vd., 1996; McNeill, 1985; 1992). İkinci grup jestler, araştırmacılar tarafından vurgulayıcı jestler (beat gestures) olarak adlandırılan jestlerdir. Vurgulayıcı jestler, semantik anlam içermeyen ritmik ve tekrarlayıcı basit motor hareketler olarak tanımlanmaktadır (Alibali, 2005; Ekman \& Freisen, 1969; Frick 1991; Krauss vd., 1996; McNeill, 1985). Üçüncü grupta bulunan jestler ise kendini düzenleme jestleridir (self adaptors). Bu sınıfta bulunan jestler, genelde kişinin zaman kazanmak için kullandığ 1 jestlerdir. Kendini düzenleme jestleri, semantik bir anlam içermemekle birlikte çoğu zaman bir gerginlik durumunu göstermek için kullanılmaktadır (Mahl, 1968).

Jestlerin beden, dil ve zihin arasındaki ilişkilerin varlığını gösterdiğini düşünen araştırmacılar, bu durumu Bedenlenmiş Biliş Teorisi (BBT; Embodied Cognition Theory) ile açıklamaktadır (Alibali \& Nathan, 2007; Goldin-Meadow \& Beilock, 2010; Hostetter \& Alibali, 2004; 2008; McNeill, 2005). Bilgi edinme sürecinde beden ile biliş arasındaki ilişkiyi açıklayan BBT'ye göre bir kavramın anlamı onun bedenimizle olan ilgisi ve çevresi ile olan ilişkilerinden ortaya çıkmaktadır (Yalvaç vd., 2011). BBT’ye göre gerçek dünya hakkındaki deneyimler yaşamın ilk yıllarından itibaren birden fazla duyu kanalı kullanılarak edinilmeye başlanır (Smith \& Gasser, 2005). Çevredeki kavramlara ilişkin algılar oluşturulur. Algıların edinilmesinde ise hareket önemli bir yer tutmaktadır (Lindbolm, 2015). Kavramlara ilişkin algılar, kişinin zihinsel imgelerini oluşturur (Beilock \& Holt, 2007; Hostetter \& Alibali, 2008; Shapiro, 2011). Jestler ise kişinin zihnindeki kavramlara ilişkin imgeleri dış dünyaya aktarmasının bir yoludur. Bu durumda jestler, yalnızca dinleyenin sözel ifadeleri anlaması ve dikkatini sürdürmesi için kullanılan el, kol hareketleri olmaktan çıkarak ayrıca konuşan kişinin bilişsel süreçleri ile yakından ilişkili hareketler olmaktadır (Hostetter \& Alibali, 2008).

Alanyazında yapılan bazı araştırmalarda konuşan kişinin, jestleri kendi bilişsel süreçlerini kolaylaştırmak için kullandığı sonucuna ulaşılmıştır (Alibali vd., 2001; Doherty-Sneddon \& Kent, 1996; Mahl, 1968). Jestlerin bilgi toparlama (Krauss, Chen \& Gotfexnum, 2000), leksikal ulaşım (LU; Lexical Access) (Krauss vd., 2000), dilimin ucunda durumu (DUD; Tip of the Tongue State, TOTs) (Beattie \& Coughlan, 1999) gibi bilişsel süreçlerde kullanıldığı bilinmektedir. Araştırmalara göre bu süreçlerde jestler, zihindeki imgelerin aktive edilmesinde önemli rol oynamaktadır (Bavelas vd., 2008; Hadar \& Butterworth, 1997). Bilişsel süreçlerden LU süreci, zihinde bulunan kavramın fonetik karşılığının bilinçaltından çekilerek ifade edilmesi olarak tanımlanabilir (Butterworth, 1989). Levelt ve diğerlerine göre (1999) göre LU, kendi içinde alt süreçleri bulunan, günlük yaşam içinde hızla ve defalarca gerçekleştirilen bilişsel bir süreçtir. LU kavramsal hazırlık basamağ i ile başlar. Bu basamakta konuşmacı 
konuşacağı kavramı zihninde aktive eder. Örneğin konuşmasında 'kare' kelimesini kullanacak kişi önce zihninde bu kavramı canlandırır. Bu canlandırmadan sonra zihinde bulunan binlerce ilişkili kelime arasından 'kare' sözcügünü seçer. Bu seçim aşaması leksikal seçim olarak adlandırılmaktadır ve saniyede iki ila üç kelimenin zihinden hızla geçmesi ile oluşmaktadır. Bu aşamadan sonra kelimenin zihindeki morfolojik karşılığı seçilir. Leksikal seçim esnasında 'kare' kelimesini seçen kişi, kelimeyi oluşturan ses bilgisel yapıyı seçer. Bu aşamadan sonra fonetik kodlama süreci başlar. Fonetik kodlama sırasında kişi kelimeyi seslendirir. Kelimenin seslendirilmesi esnasında kendini izleme süreci de devreye girer ve sesletilen kelimenin doğru ya da yanlış seçilmesi ya da yanlış sesletilmesi gibi durumlarda, kişi en başa geri dönebilir ve doğru kelimeyi bulmak için süreci tekrar başlatabilir. Jestlerin, LU sürecinde ulaşılmak istenen kelimenin konuşmacı tarafından kolay hatırlanmasını sağladığı düşünülmektedir (Hadar \& Butterworth, 1997; Krauss vd., 2000; Rauscher vd., 1996).

Bazı araştırmacılar katılımcıların yüz yüze dialog halinde olduklarında, yüz yüze dialog halinde olmayan katılımcılara göre daha fazla sembolik jest sergilediklerini ve katılımcıların kullandıkları jest sıklığının zor bilgileri aktarırken artı̆̆ııı rapor etmişlerdir. Bavelas ve diğerleri (2008) kişilerin telefonla konuşurken ya da monolog halinde iken bile jest kullanmayı sürdürdüklerini rapor etmiştir. Mol ve Kita (2012), bir olayı anlatırken kullanılan jest sayısının kullanılan sözel ifadelerin sayısını da etkilediğini, jestlerin bilişsel süreçleri toparlayıcı özelliği olduğunu ifade etmiştir. Ayrıca bilişsel süreçlerde yaşanan güçlüklerin kullanılan jest sayısını etkilediği araştırmacılar tarafından rapor edilirken (Hostetter vd., 2007; Kita \& Davies, 2009; Melinger \& Kita, 2007), jestlerin engellenmesi durumunda da konuşma ve bilgi toparlama sürecinin etkilendiği bilinmektedir (Morsella \& Krauss, 2004). Rauscher (1992) yapmış olduğu bir çalışmada, jest kullanmaları serbest olan katılımcıların LU süreci ile daha kolay ve akıcı olarak baş ettiklerini, jestleri engellenen katılımcıların ise LU sürecinde daha fazla zorluk yaşadıklarını, durakladıklarını ve gereksiz ifadeler kullandıklarını göstermiştir. Diğer taraftan Hostetter ve diğerleri (2007) yapmış oldukları başka bir çalışmada, kişilerin ellerini hareket ettirmeleri tamamen engellense bile, baş, boyun ve bacaklarını kullanarak, jeste benzer hareketler sergileyebildiklerini gözlemlemişlerdir. Çalışma sonunda el hareketi olmasalar da bu jest benzeri hareketlerin de bilişsel süreçleri kolaylaştırmaya hizmet edebileceğini ifade etmişlerdir.

Jestlerin kullanımının cinsiyet (Mahl, 1968), yaş (Feyereisen \& Havard, 1999), fiziksel ve bilişsel yeterlilik (Frick-Horbury \& Guttentag, 1998), sözel performans gibi değişkenlere göre farklılaştı̆̆ 1 alanyazında sıkça rapor edilmektedir. Jestlerin zihinsel imgelerin aktarılmasında kullanılan motor hareketler olduğu düşünüldüğünde ise, görmeye dayalı deneyimlerin zihinsel imgeleri oluşturmada önemli bir bileşen olduğu söylenebilir. Görme yetersizliği (GY), erken çocuklukta bağımsız hareket, motor, bilişsel ve sosyal iletişim gibi beceri alanlarında sinırlılıklara yol açabilmektedir (Pérez-Pereira \& Castro, 1992). Jestlerin edinimini sosyal öğrenmeler, modeli izleme ve taklit etme gibi görsel girdilerle ilişkilendiren araştırmacılar GY'nin jest kullanımında doğal olarak sınırlılıklara yol açacağını düşünmektedirler (Frame, 2000; Sharkey vd., 2000). Diğer taraftan jestlerin ediniminde tek etkenin görsel girdiler olmadığını ifade eden araştırmacılar ise, jestlerin konuşmanın doğal sürecinin bir getirisi olduğunu ifade etmektedirler (Iverson \& Goldin-Meadow, 1997; 1998; Iverson vd., 2000). GY olan bireyler, işitsel ve dokunsal girdiler gibi diğer duyu kanallarından yararlanarak (Cattaneo vd., 2008) zihinsel imaj oluşturabilmektedirler (Knauff \& May, 2006) ve sonuç çıkarma süreçlerinde farklı duyusal deneyimleri kullanarak gören bireylerle benzer sonuçları çıkarabilmektedirler (Eardley \& Pring, 2014; Noordzij vd., 2007).

Alanyazın incelendiğinde GY olan bireylerle yapılmış jest çalışmalarının iletişimsel süreçlerde kullanılan jestler üzerine olduğu (Frame, 2000; Iverson vd., 2000; Mallineni vd., 2006; Sharkey vd., 2000) ve çalışmalarda sözel performans değişkeninin kontrol altına alınmadığı görülmektedir (Frame, 2000; Sharkey vd., 2000). Ancak GY olan bireylerin bilişsel süreçlerde jestlerden yararlanıp yararlanmadıkları ve bu süreçlerde jest kullanma düzeylerinin gören bireylerden farklılaşıp farklılaşmadıkları alanyazında daha önce çalışılmamış bir konu olarak göze çarpmaktadır. Jestlerin ediniminin ve kullanımının hareket, algı, görsel imaj kavramları ile yakından ilgili olduğu düşünüldüğünde, görsel girdilerin olmaması durumunun jest kullanımını nasıl etkilediği bilinmekle birlikte (Iverson \& Goldin-Meadow, 1997; 1998; Iverson vd.,2000), jestlerin engellenmesi durumunun GY olan bireylerin LU süreci sonundaki başarılarını nasıl etkileyeceği merak konusudur. GY olan bireylerin gören bireylerle benzerlik gösterip göstermeyeceğinin belirlenmesinin, görme duyusu, jestler ve zihin arasındaki bağların anlaşılmasında son derece önemli ipuçları sağlayacağı düşünülmektedir. Ayrıca her iki gruptaki katılımcıların jestler engellenmiş ve jestler serbest koşullarında LU süreci sonunda başarılarının farklılaşıp farklılaşmadığının belirlenmesi, jest kullanımının GY olan ve gören katılımcıların bilişsel süreçlerini nasıl etkilediğinin anlaşılması bakımından da önem arz etmektedir. 
$\mathrm{Bu}$ problem durum doğrultusunda araştırmanın genel amacı, jest kullanmanın GY olan ve gören yetişkinlerin LU sürecine etkisinin karşılaştırılması olarak belirlenmiştir. Bu genel amaç doğrultusunda aşağıda sıralanan alt amaçlara cevap aranmıştır:

1. GY olan ve gören katılımcıların jest kullanımı serbest koşulunda, LU sürecinde sembolik, vurgulayıcı ve kendini düzenleme jest kullanım sıklık puanları ve her üç jest türünün toplam sıklık puanları gruplar arasında farklılaşmakta mıdır?

2. GY olan ve gören katılımcıların jest kullanımı serbest ve jest kullanımı engellenmiş koşullarında LU süreci sonunda doğru yanıt verme sıklık puanları gruplar arasında farklılaşmakta mıdır?

3. GY olan ve gören katılımcıların jest kullanımı serbest ve jest kullanımı engellenmiş koşullarında LU süreci sonunda doğru yanıt verme sıklık puanları gruplar içerisinde farklılaşmakta mıdır?

\section{Yöntem}

\section{Araştırma Deseni}

$\mathrm{Bu}$ çalışmada deneysel desen kullanılmıştır. Çalışma $2 \times 2$ tekrarlı ölçümler tasarımı olarak gerçekleştirilmiştir. Tekrarlı ölçümler tasarımında, katılımcıların hepsi araştırmada yapılan deneyin tüm koşullarına dâhil edilir (Johnson \& Christensen, 2014). Bu çalışmada a) jest kullanımının serbest olduğu ve b) jest kullanımının engellendiği iki koşul bulunmaktadır. GY olan ve gören tüm katılımcılar, jest kullanımı serbest ve jest kullanımı engellenmiş koşullarının her ikisinde de yer almıştır.

Araştırmanın bağımsız değişkeni jestleri kullanma (jestler serbest) ve kullanmama (jestler engellenmiş) durumudur. Bağımlı değişkenler ise sembolik jestlerin kullanım sıklı̆ğ puanı, vurgulayıcı jestlerin kullanım sıklığı puanı, kendini düzenleme jestlerinin kullanım sıklı̆̆ puanı, her üç jestin toplam kullanım sıklığı puanı ve LU sonunda doğru yanıt verme sıklığı puanıdır.

\section{Katılımeılar}

Araştırmanın duyuruları Gazi Üniversitesi, Öğrenme Gelişim ve Eğitim Araştırma Merkezi aracılığı ile gerçekleştirilmiş, bu duyurulara ek olarak sosyal medyadan yapılan duyurular ve Ankara'da bulunan görme engelliler derneklerinden yapılan duyurular aracılığ Katılımcıların yaş, cinsiyet ve eğitim düzeyi gibi demografik bilgilerini toplamak için uygulamacı tarafından hazırlanan Katılımcı Bilgi Formu kullanılmıştır. Katılımcılar belirlenirken a) GY olan ve gören katılımcıların benzer yaş, cinsiyet ve eğitim düzeyinde olmaları; b) katılımcıların Sözel Akıcılık Testi'nin (SAT; Verbal Fluency Test) harf akıcılı̆̆ alt testinden ortalama en az 15 kelime, kategorik akıcılık alt testinden ise en az 21 hayvan ismi üretmeleri ve katılımcıların birbirleriyle benzer puanlara sahip olması; c) GY olan katılımcıların doğuştan total ya da ağır görme yetersizliğinin olması, doğuştan ağır görme yetersizliği olan katılımcıların en iyi gördükleri dönemde görmelerini işlevsel olarak kullanmadıklarını beyan etmeleri ve çalışmaya dâhil oldukları dönemde total göme yetersizliklerinin olması ve son olarak d) katılımcıların araştırmaya katılmak için gönüllü olmaları ölçütleri aranmıştır.

Duyurulara cevap veren GY olan katılımcılardan biri, gören katılımcılardan ise ikisi belirlenen uygulama randevusuna katılmamışlardır. Randevulara katılan adaylar ile yapılan görüşmeler sonunda GY olan katılımcılardan görmesini sonradan kaybeden beş katılımcı en iyi gördükleri dönemde görmelerini işlevsel olarak kullandıklarını beyan etmiştir. Bir gören katılımcı ise ana dilinin Türkçe olmadığını beyan ettiği için araştırmaya dâhil edilmemiştir. Yapılan görüşmeler sonunda toplam $22 \mathrm{GY}$ olan ve 26 gören katılımcı adayına SAT uygulanmıştır. SAT sonunda iki GY olan ve altı gören katılımcı SAT'ın harf akıcılığı testinden ortalama 15 kelime, kategorik akıcılık testinden ise ortalama 21 hayvan ismi üretemediği için bir gören katılımcı ise uygulamayı yarım bıraktığı için uygulamaya dahil edilmemiş̧ir.

Araştırmaya, katılımcı ölçütlerini karşılayan $20 \mathrm{GY}$ olan yetişkin ile 20 gören yetişkin katılmıştır. Katılımcı sayısı nedeniyle (Köklü vd., 2007) katılımcı grupların yaşlarının karşılaştırılmasında Mann-Whitney U Testi kullanılmıştır. Buna göre GY olan katılımcıların yaş ortalamalarına $(\bar{X}=26.45, S S=7.16)$ bağlı sıra ortalamaları (20.58) ile gören katılımcıların yaş ortalamalarına $(\bar{X}=26.30, S S=6.97)$ bağlı sıra ortalamaları (20.43) arasında $(U=198.50, p=.96>.05)$ anlamlı farklılık olmadığı, yaş düzeylerinin birbirine denk olduğu anlaşılmıştır. Katılımcıların cinsiyet ve eğitim düzeylerine ilişkin bilgiler Tablo 1'de yer almaktadır. 
Tablo 1

Katılımcıların Cinsiyet ve Ĕgitim Durumlarına Göre Dă̆llımları

\begin{tabular}{|c|c|c|c|c|c|}
\hline \multirow{2}{*}{\multicolumn{2}{|c|}{ Demografik özellik }} & \multirow{2}{*}{$\begin{array}{c}\text { Gören } \\
n\end{array}$} & \multirow{2}{*}{$\%$} & GY olan & \multirow{2}{*}{$\%$} \\
\hline & & & & $n$ & \\
\hline \multirow{2}{*}{ Cinsiyet } & Kadın & 6 & 30 & 6 & 30 \\
\hline & Erkek & 14 & 70 & 14 & 70 \\
\hline \multirow{3}{*}{ Eğitim düzeyi } & Üniversite öğrencisi & 13 & 65 & 12 & 60 \\
\hline & Üniversite mezunu & 6 & 30 & 7 & 35 \\
\hline & Yüksek lisans mezunu & 1 & 5 & 1 & 5 \\
\hline
\end{tabular}

\section{Katılımcıların Sözel Performansının Belirlenmesi}

Katılımcıların sözel performanslarının belirlenmesinde SAT kullanılmıştır. SAT sözel performansı ölçen k1sa ve pratik bir testtir (Lezak vd., 2012; Troyer, 2000; Troyer vd., 1997). SAT'ın özellikle LU becerilerini değerlendirme konusunda geçerli olduğu farklı özellikte katılımcıların katıldığı pek çok çalışmada görülmüştür (Cohen vd., 1999; Seiger-Gardner \& Brooks, 2008; Weckerly vd., 2001). Test sürecinde katılımcının kategorik (semantik) akıcılık ve harf (fonetik) akıcılık performansını değerlendirmek üzere iki ayrı süreç uygulanmıştır (Lezak vd., 2012; Troyer, 2000; Troyer vd., 1997).

Çalışmada SAT’ın Fonetik akııılık testinde katılımcılara sırasıyla K, M, T harfleri verilerek, bu harfle başlayan kelimeler türetmeleri istenmiştir. Harf sırası katılımcılara altı farklı kombinasyonda ve karışık olarak sunulmuştur. Katılımcıya "Bana bir dakika boyunca söyleyebildiğiniz kadar K harfi ile başlayan kelimeler söylemenizi istiyorum” denmiş ve katılımcının cevapları video ile kaydedilmiştir. Her bir harf için katılımcıya aynı süreç uygulanmıştır.

Fonetik akıcılık testinin ardından katılımcıya kategorik akıcılık testi uygulanmıştır. Katılımcıya hayvanlar kategorisi verilerek "Şimdi bana bir dakika içinde söyleyebildiğiniz kadar hayvan ismi söylemenizi istiyorum" denmiş ve katılımcının tepkileri kaydedilmiştir. Katılımcıların sözel performanslarının eşleştirilmesi amacıyla uygulanan bu test puanları hesaplanırken anlamsız, temel olarak tekrar edilmiş, aynı kökten türeyen kelimeler çıkarılmış ve katılımcıların sözel akıcılık puanları bu şekilde hesaplanmıştır. Taban puan belirlenirken alanyazında yapılan çalışmalar incelenerek harf akıcılığı testinden üç harf denemesinden ortalama 15 kelime üretilmesi, kategorik akıcılık testinden ise ortalama 21 hayvan ismi üretilmesi kriteri konmuştur (Hostetter vd., 2007; Lezak vd., 2012; Troyer, 2000; Troyer vd., 1997). SAT'a ilişkin puanlar her iki grup için Tablo 2'de karşılaştırılmıştır. Tablo 2 incelendiğinde GY olan katılımcılar ile gören katılımcıların fonetik sözel akıcılık puanları $(U=177, p=$ $.506>.05)$ ve kategorik akıcılı puanları arasında $(U=141, p=.109>.05)$ anlamlı farklılık olmadı̆̆ görülmektedir.

\section{Tablo 2}

GY Olan ve Gören Katılımcıların Sözel Akıcılık Testi Puanları Arasındaki Farklılı̆̆a Ait Mann-Whitney U Testi Sonuçları

\begin{tabular}{cllcccccc}
\hline Sözel Akıc1lık Testi & Grup & $N$ & $X$ & $S$ & Sira ortalamas1 & Sira toplam1 & $U$ & $p$ \\
\hline \multirow{2}{*}{ Fonetik akıcılık puanları } & Gören & 20 & 16.41 & 2.52 & 19.35 & 387 & \multirow{2}{*}{177} & .50 \\
& GY olan & 20 & 16.66 & 2.19 & 21.65 & 433 & & \\
\multirow{2}{*}{ Kategorik akıc1lık puanları } & Gören & 20 & 25.70 & 4.47 & 23.45 & 469 & \multirow{2}{*}{141} & .10 \\
& GY olan & 20 & 23.20 & 4.61 & 17.55 & 351 & \\
\hline
\end{tabular}

\section{Veri Toplama Araçları}

Veri toplama sürecinde ilk aşamada katılımcıları belirlemek, demografik bilgilerini toplamak ve grupları mümkün olduğunca eşitlemek amacı ile birinci uygulamacı tarafından Katılımcı Bilgi Formu hazırlanmış ve formlar katılımcı beyanları doğrultusunda doldurulmuştur. Uygulamalarda kullanmak için birinci uygulamacı tarafından hazırlanmış 30'ar kelimeden oluşan iki grup Hedef Kelime Listesi kullanılmıştır.

\section{Hedef Kelime Listesi}

Jest kullanmanın LU sürecine etkisini belirlemek amacıyla GY olan ve gören katılımcılara 30'ar kelimeden oluşan iki grup hedef kelime listesi sunulmuştur. Kelime grupları oluşturulurken üç basamaktan oluşan bir süreç izlenmiştir. Basamaklar sırası ile kelime havuzunun oluşturulması, olası hedef kelime listesinin belirlenmesi ve hedef kelime gruplarının oluşturulmasıdır. 
İlk basamakta zihinde somut birtakım imgeler uyandıran, dolayısıyla jest sergilenme olasılığının yüksek olduğu 250 kelimeden oluşan bir kelime havuzu oluşturulmuştur (Beatie \& Coughlan, 1999; Frick-Horbury \& Guttentag, 1998; Pine vd., 2007; Rubin \& Friendly, 1986). İkinci basamakta kelime havuzunda bulunan, günlük yaşamda kullanma sıklığı milyonda üçten yüksek olan kelimeler kelime havuzundan çıkarılmıştır (Aksan vd., 2012). Bu eleme sonunda kalan 110 kelimenin sözlük anlamları Türk Dil Kurumunun çevrimiçi kullanıma açık olan Büyük Türkçe Sözlüğünden bulunmuştur. Oluşturulan olası hedef kelime listesi, jest konusunda çalışan üç ayrı alan uzmanının görüşüne sunulmuş ve kelimelerin yapılacak çalışmanın amaç ve yöntemine uygun olup olmadığı konusunda görüşleri alınmıştır. Üçüncü basamakta, uzmanların ortak olarak uygun görüş belirttiği 88 kelime çalışmaya katılması planlanan katılımcılarla benzer özellikteki iki GY olan ve iki gören yetişkine sunulmuştur. Katılımcıların dördünün de anlamını karmaşık bulduğu, başka kelime ile karıştırdığı ve anlamadığı kelimeler listeden çıkarılmıştır. Tüm bu ölçütler ve eleme basamaklarının sonunda toplam 60 sözcük, kullanım sıklıkları bakımından eşlenerek 30'ar kelimelik iki hedef kelime listesine dönüştürülmüştür. Uygulamada herhangi bir karışıklık yaşanmaması için listeler A ve B olarak isimlendirilmiştir (bk. Ek A).

\section{Uygulama}

Araştırmanın yapılması için gerekli yasal ve etik izinler için Gazi Üniversitesi Etik Kurulu Komisyonuna başvurulmuştur. İlgili komisyon kurulundan 12/05/2017 tarihli E. 70204 sayllı olur izni alındıktan sonra uygulamalar, Gazi Üniversitesi, Öğrenme Gelişim ve Eğitim Araştırma Merkezi’nde gerçekleştirilmiştir. Uygulama yapılacak odanın dış seslerden etkilenmemesine ve yalnızca uygulamacı ile katılımcının bulunduğu bir oda olmasına dikkat edilmiştir. Uygulamada, katılımcının rahat oturabileceği bir sandalye, kamera ve kronometre hazır bulundurulmuş, video kaydı ile katılımcının tepkileri kayıt altına alınmıştır. Katılımcı kamera kaydı yapılacağına dair önceden bilgilendirilmiş sözlü ve yazılı onayı alınmıştır. Araştırma uygulamalarında hedef kelime listelerinde bulunan kelimelerin anlamı katılımcılara jestler serbest ve jestler engellenmiş olmak üzere iki ayrı koşulda sunulmuştur.

Uygulamaya başlamadan önce katılımcıya “Çalışmamızda 30' ar kelimeden oluşan iki farklı hedef kelime listemiz vardır. Size bu hedef kelime listesinden bir kelimenin sözlük anlamını okuyacağım ve anlamını okuduğum kelimeyi tahmin etmenizi isteyeceğim. Kelimeyi tahmin etmek için 45 saniyeniz olacak. Ben size kelimenin anlamını okuyup bitirdikten sonra kelimeyi biliyorsanız cevabınızı söyleyiniz. Kelimeyi bilmediğinizi düşünüyorsanız süre bitene kadar düşünebilirsiniz ve tahmininizi söyleyebilirsiniz." denilmiştir. Katılımcının süreci daha kolay anlayabilmesi için listede bulunmayan iki kelime ile örnek denemeler yapılmıştır. Denemelerin ardından uygulamaya geçilmiştir.

\section{Jestler Serbest Koşulu}

Jestler serbest koşulunda katılımcının ellerini serbestçe hareket ettirmesine izin verilmiştir. Kelime listesinde bulunan kelimenin anlamı okunmuş, katılımcının tahmin süresi kronometreden başlatılmıştır. Katılımcı kendisine okunan tanımın ardından doğru cevabı verdiyse "Şimdi diğer kelimeye geçiyoruz." denilmiş, yeni kelimenin anlamı okunmuş ve süre yeniden başlatılmıştır. Katılımcı bir cevap vermiş, sonra hemen cevabını değiştirmiş ise katılımcının net olarak cevabını söylemesi istenmiştir. Katılımcı "Bilmiyorum" cevabını verdiğinde ise 45 saniyenin sonuna kadar beklenmiş ve yeni kelimeye geçilmiştir. Katılımcının tahmin süresi dolduğunda kendisine sürenin dolduğu söylenmiş ve yeni kelimenin anlamı okunmuştur. 30 kelimelik kelime listesi bittikten sonra katılımcıya uygulamanın bu basamağının bittiği söylenmiştir.

\section{Jestler Engellenmiş Koşulu}

Jestler engellenmiş koşulunda katılımcıya "Sağ elinizi sağ bacağınızın altında, sol elinizi de sol bacağınızın altında kalacak şekilde yerleştirin ve ellerinizi hareket ettirmeyin" denilerek, katılımoının jestleri kullanması engellenmiştir. Daha sonra kelime listesinde bulunan kelimenin anlamı okunmuș, katılımıııın tahmin süresi kronometreden başlatılmıştır. Katılımcı tanımın ardından doğru cevabı verdiyse "Şimdi diğer kelimeye geçiyoruz." denilmiş, yeni kelimenin anlamı okunmuş ve süre yeniden başlatılmıştır. Katılımcı bir cevap vermiş, sonra hemen cevabını değiştirmiş ise katılımcının net olarak cevabını söylemesi istenmiştir. Katılımcı "Bilmiyorum" cevabını verdiğinde ise 45 saniyenin sonuna kadar beklenmiş ve yeni kelimeye geçilmiştir. Katılımcının tahmin süresi dolduğunda kendisine sürenin dolduğu söylenmiş ve yeni kelimenin anlamı okunmuştur. 30 kelimelik kelime listesi bittikten sonra katılımcıya uygulamanın bu basamağının bittiği söylenmiştir. Uygulama sürecinde ilk katılımcıya A grubundaki kelimeler jestler serbest koşulunda sunulmuşsa, B grubundaki kelimeler jestler engellenmiş koşulunda sunulmuştur. Bir sonraki katılımcıya ise A grubundaki 
kelimeler jestleri engellenmiş olarak sunulmuşsa, B grubundaki kelimeler jestler serbest koşulunda sunulmuştur. Ayrıca kelime gruplarında bulunan kelimelerin sıraları karıştırılmıştır.

\section{Verilerin Kodlanması ve Puanlanması}

\section{Jestlerin Kodlanmast ve Puanlanmast}

Çalışmada jestler kodlanırken yalnızca el, kol ve parmakların kullanıldığı jestler dikkate alınmıştır. Jestler, sembolik, vurgulayıcı ve kendini düzenleme jestleri olarak üç kategoride kodlanmıştır (Beattie \& Coughlan, 1999; Frick, 1991). Aşağıda bu kategorilerin işlevsel tanımlarına yer verilmiştir. Katılımcı bir kelimeyi tahmin ederken birden fazla jest kullandıysa jestler arasındaki başlangıç ve bitiş ölçütü olarak ellerin denge halinde bulunmasına ve denge halini terk etmesine dikkat edilmiştir (Beatie \& Coughlan, 1999).

Buna göre;

1. Ellerin hareket halinde iken bir saniyeden az da olsa boşlukta durması ya da katılımcının ellerini bir saniyeden az bir süreliğine kendi vücuduna koyması,

2. Birbirinin ardından gelen iki farklı sınıftan jestin arasında ellerin bir saniyeden az da olsa boşlukta kalması. Örneğin hedef kelimeyi betimler biçimde sembolik jest kullanımının hemen ardından vurgulayıc jest kullanılması,

3. Katılımcının elleri hareket halinde ya da boşlukta dururken katılımcı herhangi bir türden jest kullanması, hemen ardından hiçbir duraklama olmadan ya da farklı türde bir jest kullanmadan aynı türde başka bir jest kullanması durumunda sergilenen jest tek jest olarak kabul edilmiştir (Beatie \& Coughlan, 1999).

Sembolik Jestler. Bir nesnenin nasıl kullanıldığını ya da işlevini, bir hareketi, bir şekli ya da konumu anlatabilmek için kullanılan ve semantik anlam içeren hareketlerdir (Beattie \& Coughlan, 1999; Frick, 1991; McNeill, 1992). Örneğin, 'bumerang' kelimesini anlatan kişinin işaret parmağı ile dönme hareketi yapması, sembolik jest olarak kodlanmıştır.

Vurgulayıcı Jestler. Semantik anlam içermeyen ritmik ve tekrarlayıcı basit motor hareketlerdir (Beattie \& Coughlan, 1999; Frick, 1991). Örneğin, konuşmacının konuşurken elini içeri ya da dışarı doğru ritmik bir biçimde çevirmesi, parmağını şıklatması vurgulayıcı jest olarak kodlanmıştır.

Kendini Düzenleme Jestleri. Kişinin kodlama esnasında karşılaştığ güçlüklerle başa çıkmak ve karşısındaki kişinin tutumsal çıkarımlarda bulunmasını sağlamak için kullandığı el hareketleridir (Beattie \& Coughlan, 1999). Örneğin kişinin saçını düzeltmesi, burnunu kaşıması, çenesini ovuşturması kendini düzenleme hareketi olarak kodlanmıştır.

Jestler kodlanırken ve puanlanırken, video kayıtları tekrarlı olarak izlenmiştir. Kelimenin sözlük anlamının uygulamacı tarafından okunmasının hemen ardından katılımcının her bir el hareketi izlenmiş ve uygun jest kategorisine kodlanmıştır Bunun için katılımcı jest sergilediğinde video durdurulmuş, jestin sergilendiği saniye, jestin sergileniş şekli ve jestin hangi sınıfa ait olduğu not edilmiştir. Ardından video izlemeye devam edilmiştir. Katılımcı kelimeye ilişkin tahminini söyleyene kadar kodlama sürecine devam edilmiştir. Katılımcının sergilediği her bir jest için 1 puan verilmiştir. Ancak katılımcı kelimeyi tahmin ederken, tahmin dışı konuşma yapmış ve bu konuşmaya iliş̧kin herhangi bir jest sergilemişse bu kodlama dışında bırakılmıştır. Kodlama sonunda her bir katılımcının sembolik, vurgulayıcı ve kendini düzenleme jestleri olmak üzere üç ayrı kategorideki jestleri sayılarak toplanmış, böylece jest kullanım sıklık puanları elde edilmiştir.

\section{LU Süreci Sonunda Doğru Yanıt Vermenin Kodlanmast ve Puanlanması}

Uygulamacının kelimenin sözlük anlamını okumasının hemen ardından katılımcının tahmin etme süreci başlamış olarak sayılmıştır. Katılımcının kelimeyi doğru tahmin etmesi durumunda LU başarılı olarak kodlanmış ve 1 puan verilmiş̧ir. Katılımcı kelimeyi yanlış tahmin etmiş, bilmediğini ifade etmiş ya da hiçbir tahminde bulunamamışsa, LU başarısız olarak kodlanmış ve 0 puan verilmiştir. Katılımcı LU sürecinde bir tahminde bulunmuş ve bulunduğu tahmini hemen değiştirmişse, son verdiği cevabı doğru ise 1 , yanlış ise 0 puan verilmiştir. LU süreci sonunda doğru yanıt verme sıklığı puanları, katılımcının verdiği doğru yanıtların sayısı toplanarak hesaplanmıştır. 


\section{Gözlemciler Arası Güvenirlik}

Güvenirlik çalışmasına başlanmadan önce ikinci gözlemciye uygulama boyunca kullanılan araçlar, jestlerin ve LU başarısının kodlama kurallarına ilişkin bilgi verilmiş, kodlamada bağımsılaşması sağlanmıştır. İkinci gözlemci rastgele seçilen video kayıtlarından $(n=12)$ kodlama yapmıştır. Gözlemciler arası güvenirlik [Görüş birliği / (Görüş birliği + Görüş ayrılığı) x 100] (House vd., 1981) formülü kullanılarak \%94 olarak hesaplanmıştır.

\section{Uygulama Güvenirliği}

Yapılan uygulama basamaklandırılarak Uygulama Güvenirliği Formu hazırlanmıştır. Uygulama güvenirliği ikinci bir gözlemci tarafından rastgele seçilen $(n=12)$ video kayıtları izlenerek, formda bulunan basamaklar uygulamacı tarafından yapıldı ise 'yaptı', yapılmadı ise 'yapmadı' olarak kodlanmıştır. Toplam 20 basamakta incelenen çalışmanın uygulama güvenirliği [(Gözlenen araştırmacı davranışı/ Planlanan araştırmacı davranışı) X 100] (Billingsley vd., 1980) formülü kullanılarak \%97 olarak hesaplanmıştır.

\section{Verilerin Analizi}

Katılımcı sayısının 30’un altında olduğu durumlarda puanların normal dağılması güç olacağı için (Köklü vd., 2007) gruplar arası karşılaştırmalarda Mann-Whitney U Testi ve grup içi karşılaştırmalarda Wilcoxon İşaretli Sıralar Testi kullanılmıştır. Nonparametrik istatistiklerde bağımsız değişkenin bağımlı değişken üzerindeki anlamlı etkisinin hesaplanmasında $r=z / \sqrt{ } N$ formülü kullanılmış, alanyazınla tutarlı olarak $\geq .10$ küçük etki; $\geq .30$ orta etki; $\geq .50$ yüksek etki büyüklüğü olarak yorumlanmıştır (Cohen, 1988; Field vd., 2012).

\section{Bulgular}

\section{GY Olan Katılımcılar ile Gören Katılımcıların Jest Kullanımı Serbest Koşulunda LU Sürecinde} Kullandıkları Jestlerin Sıklık Puanlarının Karşılaştırılması

GY olan katılımcılar ile gören katılımcıların jest kullanım serbest koşulunda LU sürecinde sembolik, vurgulayıcı, kendini düzenleme jestleri ve jest kullanım toplam sıklık puanlarına ilişkin Mann-Whitney U Testi sonuçları Tablo 3'te yer almaktadır. Tablo 3 incelendiğinde katılımeı grupların sembolik jestler ve kendini düzenleme jestleri kullanım sıklıkları arasında $(U=131, p=.05>.05),(U=139, p=.09>.05)$ anlamlı farklılık olmadığı görülmektedir. Vurgulayıcı jest kullanımında, GY olan katılımcılar ile gören katılımcılar arasında $(U=$ $112, p=.01<.05)$ anlamlı farklılık olduğu, bu anlamlı farklılığın etki büyüklüğünün $r=.38$ ile orta etki $(r \geq .30)$ (Cohen, 1988; Field vd., 2012) düzeyinde olduğu anlaşılmaktadır.

Tablo 3

Katılımcı Grupların LU Sürecinde Kullandıkları Jest Türlerinin Sıklıkları ve Toplam Jest Puanları Arasındaki Farklılığa Ait Sonuçlar

\begin{tabular}{|c|c|c|c|c|c|c|c|c|c|}
\hline Jest türleri & Grup & $N$ & $X$ & $S$ & Sira ortalaması & Sira toplamı & $U$ & $p$ & $r$ \\
\hline Sembolik jestler & $\begin{array}{l}\text { Gören } \\
\text { GY olan }\end{array}$ & $\begin{array}{l}20 \\
20\end{array}$ & $\begin{array}{l}7.15 \\
6.35\end{array}$ & $\begin{array}{c}6.21 \\
11.92\end{array}$ & $\begin{array}{l}23.95 \\
17.05\end{array}$ & $\begin{array}{l}479 \\
341\end{array}$ & 131 & .05 & -.29 \\
\hline Vurgulayıcı jest & $\begin{array}{l}\text { Gören } \\
\text { GY olan }\end{array}$ & $\begin{array}{l}20 \\
20\end{array}$ & $\begin{array}{l}9.95 \\
5.35\end{array}$ & $\begin{array}{l}8.99 \\
9.26\end{array}$ & $\begin{array}{l}24.90 \\
16.10\end{array}$ & $\begin{array}{l}498 \\
322\end{array}$ & 112 & $.01^{*}$ & -.38 \\
\hline $\begin{array}{l}\text { Kendini düzenleme } \\
\text { jestleri }\end{array}$ & $\begin{array}{l}\text { Gören } \\
\text { GY olan }\end{array}$ & $\begin{array}{l}20 \\
20\end{array}$ & $\begin{array}{l}17.10 \\
23.30\end{array}$ & $\begin{array}{l}14.45 \\
13.56\end{array}$ & $\begin{array}{l}17.45 \\
23.55\end{array}$ & $\begin{array}{l}349 \\
471\end{array}$ & 139 & .09 & -.26 \\
\hline $\begin{array}{l}\text { Jest kullanım toplam } \\
\text { puanı }\end{array}$ & $\begin{array}{l}\text { Gören } \\
\text { GY olan }\end{array}$ & $\begin{array}{l}20 \\
20\end{array}$ & $\begin{array}{c}34.20 \\
35\end{array}$ & $\begin{array}{l}21.68 \\
28.88\end{array}$ & $\begin{array}{l}21.33 \\
19.68\end{array}$ & $\begin{array}{l}426.50 \\
393.50\end{array}$ & 183.50 & .65 & -.07 \\
\hline
\end{tabular}

GY Olan Katılımcılar İle Gören Katılımcıların Jest Kullanımı Serbest ve Jest Kullanımı Engellenmiş Koşullarında LU Süreci Sonunda Doğru Yanıt Verme Sıklık Puanlarının Karşılaştırılması

GY olan katılımcılar ile gören katılımcıların jest kullanımı serbest ve jest kullanımı engellenmiş koşullarında LU sürecinin sonunda doğru yanıt verme sıklık puanlarının karşılaştırılmasında kullanılan MannWhitney U Testi sonuçları Tablo 4'te yer almaktadır. Tablo 4'te jest kullanımı engellenmiş koşulunda GY olan katılımcıların LU sürecinin sonunda doğru yanıt verme sıklık puanları ile gören katılımcıların LU sürecinin sonunda doğru yanıt verme siklık puanları arasında $(U=73.50, p=.001<.05)$ anlamlı farklılık olduğu görülmektedir. Aradaki farkın etki büyüklüğünün ise $r=.54$ ile yüksek etki $(r \geq .50)$ düzeyinde olduğu görülmektedir (Cohen, 1988; Field vd., 2012). Jest kullanımı serbest durumunda LU sürecinin sonunda doğru yanıt 
verme sıklık puanları arasında her iki grup arasında $(U=112, p=.11>.05)$ anlamlı farklılık olmadı̆̆ görülmektedir.

\section{Tablo 4}

Katılımcı Grupların Jestler Serbest ve Jest Kullanımı Engellenmiş Koşularında Doğru Yanıt Puanları Arasındaki Farklılı̆̆a Ait Sonuçlar

\begin{tabular}{|c|c|c|c|c|c|c|c|c|c|}
\hline Koşullar & Grup & $N$ & $X$ & $S$ & Sira ortalamas1 & Sira toplamı & $U$ & $p$ & $r$ \\
\hline \multirow{2}{*}{ Jestler engellenmiş } & Gören & 20 & 19.35 & 3.54 & 26.83 & 536.50 & \multirow{2}{*}{73.50} & \multirow{2}{*}{.001} & \multirow{2}{*}{-.54} \\
\hline & GY olan & 20 & 14.40 & 4.27 & 14.18 & 283.50 & & & \\
\hline \multirow{2}{*}{ Jestler serbest } & Gören & 20 & 19.25 & 3.77 & 23.38 & 467.50 & \multirow{2}{*}{112} & \multirow{2}{*}{.011} & \multirow{2}{*}{-.24} \\
\hline & GY olan & 20 & 17.20 & 3.98 & 17.63 & 352.50 & & & \\
\hline
\end{tabular}

GY Olan Katılımcılar ile Gören Katılımcıların Jest Kullanımı Serbest ve Jest Kullanımı Engellenmiş Koşullarında LU Sürecinin Sonunda Doğru Yanıt Verme Sıklık Puanlarının Grup İçinde Karşılaştırılması

Tablo 5'te GY olan katılımcıların ve gören katılımcıların jest kullanımı serbest koşulunda ve jest kullanımı engellenmiş koşulunda LU sürecinin sonunda doğru yanıt verme sıklık puanları grup içinde karşılaştırılmaktadır. Tablo 5'te jest kullanımı engellenmiş durumunda GY olan katılımcıların LU sürecinin sonunda doğru yanıt verme sıklık puanları ile jest kullanımı serbest durumunda LU sürecinin sonunda doğru yanıt verme sıklık puanları arasında $(Z=-2.60, p=.009<.05)$ anlamlı farklılık olduğu görülmektedir. Aradaki farkın etki büyüklüğünün $r=.41$ ile orta etki ile yüksek etkinin arasında $(r \geq .30 ; r \geq .50)$ bir düzeyde olduğu görülmektedir (Cohen, 1988; Field vd., 2012).

\section{Tablo 5}

Katılımcı Grupların Jest Kullanım Serbest ve Jest Kullanımı Engellenmiş Koşularında Doğru Yanıt Puanlarının Grup İçindeki Karşılaştırmalarına Ait Sonuçlar

\begin{tabular}{|c|c|c|c|c|c|c|c|c|c|}
\hline Gruplar & Koşullar & $N$ & $X$ & $S$ & Sira ortalamas1 & Sira toplamı & $Z$ & $p$ & $r$ \\
\hline GY olanlar & $\begin{array}{l}\text { Jestler engellenmiş } \\
\text { Jestler serbest }\end{array}$ & $\begin{array}{l}20 \\
20\end{array}$ & $\begin{array}{l}14.40 \\
17.20\end{array}$ & $\begin{array}{l}4.27 \\
3.98\end{array}$ & $\begin{array}{c}6.50 \\
10.36\end{array}$ & $\begin{array}{c}26 \\
145\end{array}$ & -2.60 & .009 & -.41 \\
\hline Görenler & $\begin{array}{l}\text { Jestler engellenmiş } \\
\text { Jestler serbest }\end{array}$ & $\begin{array}{l}20 \\
20\end{array}$ & $\begin{array}{l}19.35 \\
19.25 \\
\end{array}$ & $\begin{array}{l}3.54 \\
3.77 \\
\end{array}$ & $\begin{array}{l}9.75 \\
8.33\end{array}$ & $\begin{array}{l}78 \\
75\end{array}$ & .07 & .94 & -.11 \\
\hline
\end{tabular}

\section{Tartışma}

$\mathrm{Bu}$ araştırmada temel olarak GY olan ve gören yetişkinlerin jest kullanmalarının LU sürecinde farklılık yaratıp yaratmadığı sorusuna cevap aranmıştır. Bu temel soru doğrultusunda ilk olarak GY olan yetişkinler ile gören yetişkinlerin jest kullanımı serbest koşulunda LU sürecinde sembolik, vurgulayıcı ve kendini düzenleme jestleri ve jest kullanım toplamlarına ilişkin sıklık düzeyleri arasında anlamlı farklılık olup olmadığı incelenmiştir. Araştırmanın sonunda, sembolik ve kendini düzenleme jestlerinin kullanım sıklıkları arasında iki grup arasında anlamlı bir farklılık elde edilmemiştir. Diğer taraftan GY olan katılımcıların vurgulayıcı jestleri gören katılımcılara göre anlamlı derecede daha az sergiledikleri sonucuna ulaşılmıştır.

GY olan katılımcıların gören katılımcılardan anlamlı derecede daha az vurgulayıcı jestler kullanmaları çalışmadan elde edilen en etkileyici sonuçlardan birisidir. Bu sonuç vurgulayıc1 jestlerin gözlem yolu ile edinildiğinin bir göstergesi olarak değerlendirilebilir. Nitekim GY olan katılımcıların vurgulayıcı jest olarak parmak şıklatma, el çırpma gibi işitsel çıktıları olan jestleri daha fazla tercih ettikleri gözlemlenmiştir. GY olan katılımcılar bu jestleri işitsel deneyimleri ile edinmiş ve sergiliyor olabilirler. Bu bulgunun aksine araştırma kapsamında incelenen sembolik ve kendini düzenleme jestlerinde gruplar arasında anlamlı farklılık olmadığı sonucuna varılmıştır. Ayrıca her iki grubun toplam jest sıklıkları arasında anlamlı bir farklılık olmayışı alanyazındaki tüm bulgular bir araya getirildiğinde anlam kazanmaktadır. Bu bulgu, GY olan yetişkinlerin farklı duyu kanallarını kullanarak jestleri edinebildikleri ve gören akranları ile benzer sıklıkta jestleri sergileyebildiklerini göstermektedir. GY olan bireylerin kullandıkları jestlerin gören akranları ile benzer olduğu yönündeki bulgular, jest ediniminin tek yolunun görsel girdiler olmadığını ifade eden araştırmaları desteklemektedir. Dokunsal birtakım girdilerle görme yetersizliğinden kaynaklanan eksiklerin giderilebileceği sembolik jestlerin kullanımında iki grubun benzer olmasının ilk açıklaması olabilir (Iverson \& Goldin-Meadow, 1997; 1998; Iverson vd., 2000). BBT'ye göre bir kavram edinilirken birden fazla duyunun kullanıldığı bazı durumlarda farklı duyuların birbirinin yerine geçtiği ifade edilmektedir (Lindbolm, 2015). Alanyazından elde edilen bu sonuçlar, GY olan katılımcıların gören katılımcılarla benzer sıklıkta sembolik jest kullanmasının ikinci bir açıklaması olarak düşünülebilir. Her iki grubun benzer sıklıkta kendini düzenleme jestleri sergilemeleri ise, bu 
jest türünün genel olarak aynı amaçlar doğrultusunda kullanıldığının bir göstergesi olabilir. Nitekim kendini düzenleme jestleri gerginlik ve anlık siniri belli etmede kullanılmasıyla karakterize edilmektedir (Mahl, 1968).

Araştırmanın ikinci araştırma sorusu çerçevesinde GY olan katılımcılar ile gören katılımcıların, jest kullanımı serbest koşulunda ve jest kullanımı engellenmiş koşulunda LU sürecinin sonunda doğru yanıt verme sıklık puanları arasında anlamlı farklılık olup olmadığı incelenmiştir. Jest kullanımı serbest durumunda katılımcı grupların doğru yanıt sıklıkları arasında anlamlı bir farklılık olmadığı, ancak jestler engellenmiş koşulunda GY olan katılımcıların doğru yanıt verme sıklığı puanlarının gören katılımcılara göre anlamlı derecede düştüğü görülmüştür. Jestler serbest koşulunda her iki katılımcı grubunun da benzer başarıyı göstermesi, jestleri kullanabilmenin her iki grupta da benzer etkileri yarattığına, jestlerin konuşma esnasında ipucu görevi üstlendiğine işaret etmektedir (Frick, 1991; Hostetter \& Alibali, 2010; Hostetter vd., 2007; Krauss vd., 1996; Rauscher, 1992; Ravizza, 2003). Çalışmadan elde edilen bu sonucun, jestlerin tıpkı gören katılımcılarda olduğu gibi GY olan katılımcılarda da benzer stratejilerle, benzer amaçlara hizmet ettiğini gösterdiği düşünülmektedir.

$\mathrm{Bu}$ çalışmadan elde edilen etkileyici sonuçlardan birisi, jest kullanımı engellenmiş durumunda GY olan katılımcıların LU sürecinin sonunda, gören katılımcılara göre daha az doğru yanıt vermeleridir. Bu çalışmada yer alan GY olan katılımcıların jest kullanımının engellenmesi durumunda gören katılımcılara göre daha az sayıda doğru kelimeye ulaşmalarının iki açıklaması olabilir. Birincisi jestlerin engellenmesi durumu, GY olan bireylerin zihinlerindeki imgeleri aktive etmelerini ve bilgiyi doğru olarak hatırlamalarını engellemiş olabilir. İkinci olası açıklama ise, GY olan bireylerin kavramlara dair imgeleri oluştururken dokunsal girdilerden yararlandıkları düşünüldüğünde (Eardley \& Pring, 2014; Knauff \& May, 2006; Noordzij vd., 2007) jest kullanımının engellenmesinin aslında bilgi kanallarının da engellenmesi anlamına gelme olasilığıdır. Bu durum GY olan katılımcıların gören katılımcılara göre daha fazla engellenmişlik yaşamalarına neden olmuş ve kelimeleri zihinden çağırmalarını güçleştirmiş olabilir. Nitekim uygulama süreci boyunca GY olan katılımcıların jestleri engellendiğinde kelimeyi bildiklerini, ancak hatılamak için en azından kendini düzenleyici jestlerden yararlanmaları gerektiğini (ör. "Kelimeyi hatırlamak için sakalımı kaşıyabilir miyim?" gibi) sıkça ifade ettikleri dikkat çekmiştir.

$\mathrm{Bu}$ araştırmanın bir diğer sonucu da GY olan katılımcıların jest kullanımları serbestken LU süreci sonunda daha fazla doğru yanıt vermeleridir. Bu sonuç, GY olan katılımcıların grup içinde jestler serbestken bilgiyi daha kolay toparlayabildiklerine ve jestleri engellendiğinde bu durumun bilgiyi toparlayıp doğru sonuca ulaşmada sınırlılık yarattığına işaret etmektedir. Gören bireylerde jestlerin kullanılmasının zihinde bulunan imgeleri somutlaştırma bakımından LU sürecinde kolaylık sağladığı, jestleri engellenen katılımcıların LU süreci sonunda doğru yanıt verme oranlarının düştüğü bilinmektedir (Frick, 1991; Frick-Horbury \& Guttentag, 1998; Hadar \& Butterworth, 1997; Hostetter vd., 2007; Krauss vd., 1996; Krauss vd., 2000; Rauscher, 1992; Ravizza 2003). Bu araştırmadan elde edilen sonuçlar ise, gören bireylerle yapılan çalıșmaların sonuçlarının GY olan bireylere de genellenebileceğini göstermektedir. Jestlerin, GY olan katılımcıların kendilerine has duyusal stratejilerle oluşturdukları zihinsel imgeleri harekete geçirerek, doğru cevaba ulaşmalarını sağladığı düşünülmektedir.

Diğer taraftan çalışma sonunda gören katılımcıların jest kullanımı serbest koşulunda ve jest kullanımı engellenmiş koşulunda LU süreci sonunda doğru yanıt verme sıklık puanları arasında anlamlı farklılık olmadığı görülmüştür. Jest kullanımının LU süreci sonunda doğru yanıt vermeye etki ettiği bilinmekle birlikte (Frick, 1991; Hostetter vd., 2007; Krauss vd., 1996; Rauscher, 1992; Ravizza, 2003), katılımcıların jestlerinin engellendiği koşullarda, başlarını, ayaklarını omuzlarını hareket ettirerek jeste benzer hareketler sergiledikleri, bu durumun da sonuçları etkileyebileceği de bilinmektedir (Hostetter vd., 2007). Bu çalışmada da gören katılımcıların jest kullanımının engellendiği koşulda ayakları ve başları ile sembolik jestlere benzer jestler sergiledikleri gözlemlenmiştir. Her ne olursa olsun bu baş, ayak ve omuz hareketlerinin de tıpkı el hareketleri gibi katılımcıların doğru tahminde bulunmasını sağlayabileceği düşünülmektedir. Nitekim aynı şartlarda GY olan katılımcıların bu hareketleri fazla kullanmadıkları, dolayısıyla jestlerinin engellendiği koşulda LU süreci sonunda daha az başarılı oldukları sonucuna ulaşıııışıtır.

Bu araştırmadan elde edilen sonuçlar göz önünde bulundurulduğunda, sembolik ve kendini düzenleme işlevindeki jestlerin ediniminde tek girdi kanalının görme duyusu olmadığı, ancak vurgulayıcı işlevde kullanılan jestlerin model alma ve taklit yolu ile edinilebileceği düşünülmektedir. Bununla birlikte gören katılımcıların jestler engellenmiş ve jestler serbest koşulunda LU süreci sonunda doğru yanıt verme sıklık puanları grup içinde farklılık görülmemişken GY olan katılımcıların grup içi puanlarının değişmesi, GY olan bireylerin bilgi ve kavram edinme sürecinde dokunsal girdilerden fazlaca yararlanmalarından kaynaklanıyor olabileceğine işaret edebilir. 
Çalışmada yer alan her iki katılımcı grubunun eğitim düzeyleri ve sözel performansları bakımından eşitlenmiş olması bu araştırmanın önemli ayırt edici özelliklerindendir. Çalışmada yer alan her iki grubun LU sürecinde jestlerden faydalandıkları sonucuna ulaşılması, grupların jestleri benzer amaçlarla kullandıkları yönünde bilgi sağlamaktadır. Dolayısıyla araştırmanın bulguları, GY olan bireylerin sembolik jestleri gören katılımcılarla aynı oranda kullanmaları farklı duyu motor deneyimlerin benzer jest çıktılarını sağladığına işaret etmektedir.

Buna ek olarak GY olan bireylere farklı öğrenme firsatlarının sağlanması, yaparak yaşayarak öğrenme deneyimlerinin sunulması, dış dünyayı algılama, zihinsel imge oluşturma ve bu imajların dış dünyaya aktarılmasında son derece önem arz eden durumlar olarak dikkat çekmektedir. BBT'nin önerdiği kavramlara ilişkin algıların birden fazla duyu kanalının beraber ve bazen birbirinin yerine kullanılarak oluşturulduğu düşünüldüğünde (Beilock \& Holt, 2007; Hostetter \& Alibali, 2008; Lindbolm, 2015; Shapiro, 2011; Smith \& Gasser, 2005), GY olan bireylere sağlanan deneyimlerin önemi bir kez daha ortaya çıkmaktadır. Jest ediniminin faklı duyu motor deneyimler ve yaşamın ilk yıllarında sağlanan çeşitli yaşantılardan etkilendiği düşünüldüğünde katılımcılarla yapılacak nitel görüşmelerle GY olan bireylere erken çocukluk döneminde sunulan öğrenme ve deneyim edinme firsatları hakkında bilgi sağlanarak jest kullanım örüntüleri arasındaki ilişkiler incelenebilir.

Her araştırmada olduğu gibi bu çalışmanın da bazı sınırlılıkları mevcuttur. Örneğin bu çalışmada yalnızca LU süreci sonundaki başarı puanları incelenmiştir. İleri çalışmalarda, katılımcıların LU süreci sonunda doğru cevaba ulaşmada harcadıkları zaman değişkeninin eklenmesi, katılımcı grupların bilişsel hızları ve LU süreci sırasında karşılaşılan güçlükler üzerinde jestlerin rolü hakkında bilgi sağlayıcı olacaktır. Elde edilen sonuçların eğitim düzeyinin bilişsel süreçlere ve jest kullanım örüntüleri üzerine etkisinin anlaşılması için eğitim düzeyi çeşitlendirilerek farklı eğitim düzeylerine (ör. ilkokul veya ortaokul) sahip katılımcıların da yer aldığı çalışmalar yapılabilir. Ek olarak, görmesini işlevsel olarak kullanan bireylerin GY sonucunda kullandıkları jestlerde oluşabilecek niteliksel bozulmaların anlaşılması bakımından, örneklem grubuna görmesini sonradan kaybeden bireyler de eklenebilir.

\section{Yazarların Katkı Düzeyleri}

Yazarlar, çalışma konusunu belirleme, araştırma deseni, veri toplama, verilerin analizi ve çalışmanın raporlanması görevlerini iş birliği içerisinde gerçekleştirmişlerdir. 


\section{Kaynaklar}

Aksan, Y., Aksan, M., Koltuksuz, A., Sezer, T., Mersinli, Ü., Demirhan, U. U., Yilmazer, H., Kurtoglu, Ö., Atasoy, G., Öz, S., \& Yildiz, I. (2012). Construction of the Turkish national corpus (TNC). In N. Calzolari, K. Choukri, T. Declerck, M. U. Doğan, B. Maegaard, J. Mariani, A. Moreno, J. Odijk, \& S. Piperidis (Eds.), Proceedings of the 8th International Conference on Language Resources and Evaluation (LREC 2012) (pp. 3223-3227). European Language Resources Association (ELRA). http://www.lrecconf.org/proceedings/lrec2012/papers.html

Alibali, M. W. (2005). Gesture in spatial cognition: Expressing, communicating, and thinking about spatial information. Spatial Cognition and Computation, 5(4), 307-331. https://doi.org/10.1207/s15427633scc0504_2

Alibali, M. W., Evans, J. L., Hostetter, A. B., Ryan, K., \& Mainela-Arnold, E. (2009). Gesture-speech integration in narrative: Are children less redundant than adults? Gesture, 9(3), 290-311. https://doi.org/10.1075/gest.9.3.02ali

Alibali, M. W., Heath, D. C., \& Myers, H. J. (2001). Effects of visibility between speaker and listener on gesture production: Some gestures are meant to be seen. Journal of Memory and Language, 44(2),169-188. https://doi.org/10.1006/jmla.2000.2752

Alibali, M. W., Kita, S., \& Young, A. J. (2000). Gesture and the process of speech production: We think, therefore we gesture. Language and Cognitive Processes, 15(6), 593-613. https://doi.org/10.1080/016909600750040571

Alibali, M. W., \& Nathan, M. J. (2007). Teachers' gestures as a means of scaffolding students' understanding: Evidence from an early algebra lesson. In Goldman, R., Pea, R., Barron, B., \& Derry, S. J. (Eds.), Video Research in the Learning Sciences (1st ed., pp. 349-365). Routledge.

Bavelas, J., Gerwing, J., Sutton, C., \& Prevost, D. (2008). Gesturing on the telephone: Independent effects of dialogue and visibility. Journal of Memory and Language, 58(2), 495-520. https://doi.org/10.1016/j.jml.2007.02.004

Beattie, G., \& Coughlan, J. (1999). An experimental investigation of the role of iconic gestures in lexical access using the tip-of-the-tongue phenomenon. British Journal of Psychology, 90(1), 35-56. https://doi.org/10.1348/000712699161251

Beilock, S. L., \& Holt, L. E. (2007). Embodied preference judgments: Can like ability be driven by the motor system? Psychological Science, 18(1), 51-57. https://doi.org/10.1111\%2Fj.1467-9280.2007.01848.x

Billingsley, F., White, O.R., \& Munson, R. (1980). Procedural reliability: A rationale and an example. Behavioral Assessment, 2, 229-241.

Butterworth, B. (1989). Lexical access in speech production. In W. Marslen-Wilson (Ed.), Lexical representation and process (pp. 108-135). MIT Press.

Calvo-Merino, B., Glaser, D. E., Grèzes, J., Passingham, R. E., \& Haggard, P. (2004). Action observation and acquired motor skills: An FMRI study with expert dancers. Cerebral Cortex, 15(8), 1243-1249. https://doi.org/10.1093/cercor/bhi007

Cattaneo, Z., Vecchi, T., Cornoldi, C., Mammarella, I., Bonino, D., Ricciardi, E., \& Pietrini, P. (2008). Imagery and spatial processes in blindness and visual impairment. Neuroscience \& Biobehavioral Reviews, 32(8), 1346-1360. https://doi.org/10.1016/j.neubiorev.2008.05.002

Cohen, J. (1988). Statistical power analysis for the behavioral sciences. Lawrence Earlbaum Associates.

Cohen, M. J., Morgan, A. M., Vaughn, M., Riccio, C. A., \& Hall, J. (1999). Verbal fluency in children: Developmental issues and differential validity in distinguishing children with attention-deficit hyperactivity disorder and two subtypes of dyslexia. Archives of Clinical Neuropsychology, 14(5), 433443. https://doi.org/10.1093/arclin/14.5.433

Doherty-Sneddon, G., \& Kent, G. (1996). Visual signals and the communication abilities of children. Journal of Child Psychology and Psychiatry, 37(8), 949-959. https://doi.org/10.1111/j.1469-7610.1996.tb01492.x 
Eardley, A. F., \& Pring, L. (2014). Sensory imagery in individuals who are blind and sighted: Examining unimodal and multimodal forms. Journal of Visual Impairment and Blindness, 108(4), 323-334. https://doi.org/10.1177\%2F0145482X1410800407

Ekman, P., \& Friesen, W. V. (1969). The repertoire of nonverbal behavior: Categories, origins, usage, and coding. Semiotica, 1(1), 49-98.

Feyereisen, P., \& Havard, I. (1999). Mental imagery and production of hand gestures while speaking in younger and older adults. Journal of Nonverbal Behavior, 23(2), 153- 171. https://doi.org/10.1023/A:1021487510204

Field, A. P., Miles, J., \& Field, Z. (2012). Discovering statistics using. Sage Publicaton.

Frame, M. J. (2000). The relationship between visual impairment and gestures. Journal of Visual Impairment and Blindness, 94(3), 155-172. https://doi.org/10.1177\%2F0145482X0009400304

Frick, D. J. (1991). The use of hand gestures as self-generated cues [Doctoral dissertation]. The University of North Carolina.

Frick-Horbury, D., \& Guttentag, R. E. (1998). The effects of restricting hand gesture production on lexical retrieval and free recall. The American Journal of Psychology, 111(1), 43-62. https://doi.org/10.2307/1423536

Goldin-Meadow, S., \& Beilock, S. L. (2010). Action's influence on thought: The case of gesture. Perspectives on Psychological Science, 5(6), 664-674. https://doi.org/10.1177/1745691610388764

Goldin-Meadow S, \& Iverson, J. M. (2010). Gesturing across the lifespan. W. F. Overton (Ed.), Cognition, Biology, and Methods Across the Lifespan (pp. 36-55). Wiley.

Goldin-Meadow, S., \& Morford, M. (1985). Gesture in early child language: Studies of deaf and hearing children. Merrill-Palmer Quarterly, 31(2), 145-176.

Hadar, U., \& Butterworth, B. (1997). Iconic gestures, imagery, and word retrieval in speech. Semiotica, 115(1-2), 147-172. https://doi.org/10.1515/semi.1997.115.1-2.147

Hauk, O., Johnsrude, I., \& Pulvermüller, F. (2004). Somatotopic representation of action words in human motor and premotor cortex. Neuron, 41(2), 301-307. https://doi.org/10.1016/S0896-6273(03)00838-9

Hostetter, A. B. (2011). When do gestures communicate? A meta-analysis. Psychological Bulletin, 137(2), 297 315. https://psycnet.apa.org/doi/10.1037/a0022128

Hostetter, A. B., \& Alibali, M. W. (2004). On the tip of the mind: Gesture as a key to conceptualization. In K. Forbus, D. Gentner, \& T. Regier (Eds.), Proceedings of the 26th Annual Conference of the Cognitive Science Society (pp. 589-594). Erlbaum.

Hostetter, A. B., \& Alibali, M. W. (2008). Visible embodiment: Gestures as simulated action. Psychonomic Bulletin \& Review, 15(3), 495-514. https://doi.org/10.3758/PBR.15.3.495

Hostetter, A. B., \& Alibali, M. W. (2010). Language, gesture, action! A test of the gesture as simulated action framework. Journal of Memory and Language, 63(2), 245-257. https://doi.org/10.1016/j.jm1.2010.04.003

Hostetter, A. B., Alibali, M. W., \& Kita, S. (2007). Does sitting on your hands make you bite tongue? The effects of gesture prohibition on speech during motor descriptions. In K. Forbus, D. Gentner, \& T. Regier (Eds.), Proceedings of the 29th Annual Meeting of the Cognitive Science Society (pp. 1097-1102). Erlbaum.

House, A. W., House, B. G., \& Campbell, M. B. (1981). Measures of interobserver agreement: Calculation formula and distribution effect. Journal of Behavioral Assessment, 3, 37-57.

Iverson, J. M., \& Goldin-Meadow, S. (1997). What's communication got to do with it? Gesture in children blind from birth. Developmental Psychology, 33(3), 453-465. https://doi.org/10.1037/0012-1649.33.3.453

Iverson, J. M., \& Goldin-Meadow, S. (1998). Why people gesture when they speak. Nature, 396(6708), 228. https://doi.org/10.1038/24300 
Iverson, J. M., \& Thal, D. J. (1998). Communication transition: There's more to the hand than meets the eye. In A. M. Wetherby, S. F. Warren, \& J. Reichle (Eds.), Transitions in prelinguistic communication (pp. 5986). Brookes.

Iverson, J. M., Tencer, H. L., Lany, J., \& Goldin-Meadow, S. (2000). The relation between gesture and speech in congenitally blind and sighted language-learners. Journal of Nonverbal Behavior, 24(2), 105-130. https://doi.org/10.1023/A:1006605912965

Iverson, J. M., \& Thelen, E. (1999). Hand, mouth and brain: The dynamic emergence of speech and gesture. Journal of Consciousness Studies, 6(11-12), 19-40.

Johnson, B., \& Christensen, L. (2014). Educational research, quantitative, qualitative, and mixed approaches (5th ed.). Sage Publications.

Kendon, A. (1994). Do gestures communicate? A review. Research on Language and Social Interaction, 27(3), 175-200. https://doi.org/10.1207/s15327973r1si2703_2

Kita, S. (2000). How representational gestures help speaking. In D. McNeill (Ed.), Language and gesture (pp. 162-185). Cambridge University Press.

Kita, S., \& Davies, T. S. (2009). Competing conceptual representations trigger co-speech representational gestures. Language and Cognitive Processes, 24(5), 761-775. https://doi.org/10.1080/01690960600696916

Knauff, M., \& May, E. (2006). Mental imagery, reasoning, and blindness. The Quarterly Journal of Experimental Psychology, 59(1), 161-177. https://doi.org/10.1080\%2F17470210500149992

Köklü, N., Büyüköztürk, Ş., \& Bökeoğlu, Ç. Ö. (2007). Sosyal bilimler için istatistik [Statistics for social sciences]. Pegem.

Krauss, R. M. (1998). Why do we gesture when we speak? Current Directions in Psychological Science, 7(2), 5460. https://doi.org/10.1111/1467-8721.ep13175642

Krauss, R. M., Chen, Y., \& Chawla, P. (1996). Nonverbal behavior and nonverbal communication: What do conversational hand gestures tell us? Advances in Experimental Social Psychology, 28, 389-450. https://doi.org/10.1016/S0065-2601(08)60241-5

Krauss, R. M., Chen, Y., \& Gotfexnum, R. F. (2000). Lexical gestures and lexical access: A process model. In D. McNeill (Ed.), Language and gesture (pp. 261-283). Cambridge University Press.

Levelt, W. J., Roelofs, A., \& Meyer, A. S. (1999). A theory of lexical access in speech production. Behavioral and Brain Sciences, 22(1), 1-38. https://doi.org/10.1017/s0140525x99001776

Lezak, M., Howieson, D., \& Loring, D. (2012). Neuropsychological assessment (5th ed.). Oxford University Press.

Lindblom, J. (2015). Embodied social cognition. Springer.

Mahl, G. F. (1968). Gestures and body movements in interviews. In J. M. Shlien (Ed.), Research in psychotherapy conference (pp. 295-346). American Psychological Association.

Mallineni, S., Nutheti, R., Thangadurai, S., \& Thangadurai, P. (2006). Non-verbal communication in children with visual impairment. British Journal of Visual Impairment, 24(1), 30-33. https://doi.org/10.1177/0264619606060033

McNeill, D. (1985). So you think gestures are nonverbal? Psychological Review, 92(3), 350-371.

McNeill, D. (1992). Hand and mind: What gestures reveal about thought. University of Chicago.

McNeill, D. (2005, July). Gesture, gaze, and ground. In International workshop on machine learning for multimodal interaction (pp. 1-14). Springer.

Melinger, A., \& Kita, S. (2007). Conceptualisation load triggers gesture production. Language and Cognitive Processes, 22(4), 473-500. https://doi.org/10.1080/01690960600696916

Melinger, A., \& Levelt, W. J. (2004). Gesture and the communicative intention of the speaker. Gesture, 4(2), 119141. https://doi.org/10.1075/gest.4.2.02mel 
Mol, L., \& Kita, S. (2012). Gesture structure affects syntactic structure in speech. In N. Miyake, D. Peebles, \& R. P. Cooper (Eds.), Proceedings of the 34th Annual Conference of the Cognitive Science Society (pp. 761766). Cognitive Science Society.

Morsella, E., \& Krauss, R. M. (2004). The role of gestures in spatial working memory and speech. The American Journal of Psychology, 117(3), 411-424. https://doi.org/10.2307/4149008

Noordzij, M. L., Zuidhoek, S., \& Postma, A. (2007). The influence of visual experience on visual and spatial imagery. Perception, 36(1), 101-112. https://doi.org/10.1068/p5390

Pérez-Pereira, M., \& Castro, J. (1992). Pragmatic functions of blind and sighted children's language: A twin case study. First Language, 12(34), 17-37.

Pine, K. J., Bird, H., \& Kirk, E. (2007). The effects of prohibiting gestures on children's lexical retrieval ability. Developmental Science, 10(6), 747-754. https://doi.org/10.1111/j.1467-7687.2007.00610.x

Pine, K. J., Lufkin, N., \& Messer, D. (2004). More gestures than answers: Children learning about balance. Developmental Psychology, 40(6), 1059-1067. https://doi.org/10.1037/0012-1649.40.6.1059

Rauscher, B. H. (1992). The role of gestures in speech production: Gestures enhance lexical access [Doctoral Dissertation]. Columbia University.

Rauscher, B. H., Krauss, R. M., \& Chen, Y. (1996). Gesture, speech, and lexical access: The role of lexical movements in speech production. Psychological Science, 7(4), 226-231.

Ravizza, S. (2003). Movement and lexical access: Do noniconic gestures aid in retrieval? Psychonomic Bulletin \& Review, 10(3), 610-615. https://doi.org/10.3758/BF03196522

Rubin, D. C., \& Friendly, M. (1986). Predicting which words get recalled: Measures of free recall, availability, goodness, emotionality, and pronunciability for 925 nouns. Memory \& Cognition, 14(1), 79-94.

Seiger-Gardner, L., \& Brooks, P. J. (2008). Effects of onset-and rhyme-related distractors on phonological processing in children with specific language impairment. Journal of Speech, Language, and Hearing Research, 51(5), 1263-1281. https://doi.org/10.1044/1092-4388(2008/07-0079)

Shapiro, L. (2011). Embodied cognition: New problems of philosophy. Routledge.

Sharkey, W. F., Asamoto, P., Tokunaga, C., Haraguchi, G., \& McFaddon-Robar, T. (2000). Hand gestures of visually impaired and sighted interactants. Journal of Visual Impairment and Blindness, 94(9), 549-563. https://doi.org/10.1177/0145482X0009400902

Smith, L., \& Gasser, M. (2005). The development of embodied cognition: Six lessons from babies. Artificial Life, 11(1-2), 13-29. https://doi.org/10.1162/1064546053278973

Troyer, A. K. (2000). Normative data for clustering and switching on verbal fluency tasks. Journal of Clinical and Experimental Neuropsychology, 22(3), 370-378. https://doi.org/10.1076/1380-3395(200006)22:3;1$\mathrm{V} ; \mathrm{FT} 370$

Troyer, A. K., Moscovitch, M., \& Winocur, G. (1997). Clustering and switching as two components of verbal fluency: Evidence from younger and older healthy adults. Neuropsychology, 11(1), 138-146. https://doi.org/10.1037//0894-4105.11.1.138

Weckerly, J., Wulfeck, B., \& Reilly, J. (2001). Verbal fluency deficits in children with specific language impairment: Slow rapid naming or slow to name? Child Neuropsychology, 7(3), 142-152. https://doi.org/10.1076/chin.7.3.142.8741

Yalvaç, B., Soylu, F., \& Arıkan, A. (2011). Bedenlenmiş biliş ve eğitim [Embodied Cognition and Education]. Ethos: Felsefe ve Toplumsal Bilimlerde Diyaloglar, 4(1), 1-20. 
Ek

\section{A Grubu Hedef Kelime Listesinden Kelime Örnekleri}

1. Siperlik: Güneş ve yağmurun etkisinden korunmak amacıyla şapka, kasket vb.nin önüne yapılan çıkıntı. $(0,01)$

2. El arabası: Elle sürülen taş, toprak vb. taşımaya yarayan, tek tekerlekli ve iki kollu, küçük araba. $(0,02)$

3. Kundak:Yeni doğmuş çocuğu ilk aylarda sıkıca sarıp sarmalamaya yarayan geniş bez. $(0,05)$

4. Çivi yazısı: Eski Farsların, Medlerin ve Asurluların kullandığı yazı. $(0,06)$

5. Miğfer: Savaşçıların veya itfaiyecilerin başlarına giydikleri demir başlık, tolga. $(0,08)$

6. Trrabzan: Merdiven korkuluğu. $(0,08)$

7. Rulo: Dürülerek boru biçimi verilmiş deri veya kâğıt tomar. $(0,08)$

8. Hortum: Hava veya suyun kendi etrafında hızla dönüp buluttan yeryüzüne uzanan sütun biçiminde oluşan, alanı dar bir firtına türü. $(0,15)$

9. Kaşağı: Hayvanları tımar etmek için kullanılan, sacdan, dişli araç. $(0,1)$

10. Abaküs: Basit sayma ve hesap işleri yapmakta kullanılan, her teline onar boncuk geçirilmiş hesap aracı, çörkü, sayı boncuğu. $(0,25)$

\section{B Grubu Hedef Kelime Listesinden Kelime Örnekleri}

1. Bukle: Küçük lüle durumunda, kıvrımlı saç. $(0,02)$

2. Ksilofon: Değişik sayıda akortlu tahta veya metal çubukların gam sırasıyla dizilmesinden oluşan, iki değnekle vurularak çalınan bir çalgı. $(0,02)$

3. İletki: Bir açıyı ölçmeye ve başka bir yerde aynı açıyı çizmeye yarayan, yarım çember biçimindeki araç. $(0,06)$

4. Tetik: Ateşli silahlarda ateşlemeyi sağlamak için çekilen küçük parça. $(0,06)$

5. Puset: Elle sürülen, hafif, küçük çocuk arabası. $(0,08)$

6. Panjur: Güneşi ve rüzgârı önlemeye, ışığı azaltmaya yarayan, açılır kapanır dar ve yatay tahtadan, plastikten veya metal gereçlerden yapılmış, pencereye takılan kapatma düzeneği. $(0,08)$

7. Steteskop: Kalbin, iç organların hareketlerini dinlemeye yarayan araç. $(0,13)$

8. Perende: Havada çark gibi dönerek atılan takla. $(0,17)$

9. Baret: İşşilerin başlarına giydikleri, metal veya plastikten yapılmış koruyucu başlık. $(0,1)$

10. Hörgüç: Devenin sırtındaki tümsek, çıkıntı. $(0,25)$

Kelimelerin TUD'dan (Aksan vd., 2012) alınan kullanım sıklıkları parantez içinde belirtilmiştir.

Kelimelerin sözlük anlamlarına Türk Dil Kurumu içinde. http://www.tdk.gov.tr sayfasından erişilmiştir. 


\section{Ankara University Faculty of Educational Sciences Journal of Special Education}

2021, 22(2), 395-417
RESEARCH

Recieved Date: 28.02.20

Accepted Date: 27.11 .20

OnlineFirst: 17.12 .20

\title{
A Comparison of the Effects of Gesture Use on the Lexical Access Process of Adults with Visual Impairments and Sighted Adults*
}

Zahide Töret ${ }^{\mathrm{iD}}$

\author{
Selda Özdemir iD 2
}

\begin{abstract}
Introduction: Gestures play a role in the lexical access process. The main purpose of this study was to compare the effects of gesture use on the lexical access of adults with visual impairments (VI) and sighted adults.

Method: A 2x2 repeated measurements design was used. 20 adults with VI and 20 sighted adults with similar demographic characteristics were recruited. The verbal performances of the participants were measured via the use of the verbal fluency test. The meanings of the words in a Target Word List were read to each participant to identify the effects of gesture use on the lexical access. After listening to each word's definition, all participants were asked to guess the related word under gesture-free or gesture-restricted conditions.

Findings: There were no differences between the frequencies of symbolic gestures and self-adaptors used by adults with visual impairments and sighted adults. However, there was a significant difference between the frequencies of beat gestures in gesture-free condition. In the gesture-restricted condition, there was a significant difference between the correct response frequencies of the word groups following the lexical access.

Discussion: The results were discussed within the framework of the relevant literature. The suggestions were made for further research and implementation.
\end{abstract}

Keywords: Visual impairments, adults with visual impairments, gestures, lexical access, embodied cognition theory.

To cite: Töret, Z., \& Özdemir, S. (2021). A Comparison of the effects of gesture use on the lexical access process of adults with visual impairments and sighted adults. Ankara University Faculty of Educational Sciences Journal of Special Education, 22(2), 395-417. https://doi.org/10.21565/ozelegitimdergisi.696281

*This study is based on the graduate thesis of the first author submitted to the Institute of Educational Sciences at Gazi University.

${ }^{1}$ Corresponded Author: Res. Assist., Gazi University, E-mail: zahidetoret@gazi.edu.tr, https://orcid.org/0000-0003-21029876

${ }^{2}$ Prof., Hacettepe University, E-mail: seldaozdemir@ hacettepe.edu.tr, https://orcid.org/0000-0001-9205-5946 


\section{Introduction}

Gestures involve the hand and arm movements that occur spontaneously during speech and thinking. They play important roles during communication and emerge in the first years of life (Hostetter, 2011; Iverson \& Thal, 1998; Kendon, 1994; McNeill, 1992). Many researchers emphasize that gestures are used not only for communication purposes but also for the regulation of more complex cognitive processes (Hostetter et al., 2000; Melinger \& Levelt, 2004; Pine et al., 2004). Some of these cognitive processes that can be listed are information packaging, lexical access, and the tip-of-the-tongue (TOT) state. It has been well documented in the literature that the parts of the brain centers related to language and body support and affect each other (Calvo-Merino et al., 2004; Hauk et al., 2004; Iverson \& Thelen, 1999).

Gestures have been defined as the hand movements which are used to make sense of a speech or to explain motor or spatial information (Alibali, 2005; Krauss, 1998). Many studies suggest that the gestures can be examined under three categories: Symbolic gestures, beat gestures, and self-adaptors. The movements with semantic meaning used to describe how an object is used, its function, its movements, or its position have been classified as "symbolic gestures" (Alibali, 2005; Frick 1991; Krauss et al., 1996; McNeill, 1985; 1992). Rhythmic and repetitive simple motor movements without semantic meanings were defined as beat gestures (Alibali, 2005; Ekman \& Freisen, 1969; Frick 1991; Krauss et al., 1996; McNeill, 1985). On the other hand, self-adaptors do not contain any semantic meaning. They are generally used by a person to save some time and indicate a state of irritation and tension (Mahl, 1968). When the gesture categories were examined, some researchers reported that there were movements used to symbolize some images in a person's mind, effect the speech, or regulate some mental processes of a person (McNeill, 1992).

According to Embodied Cognition Theory (ECT) "the meaning of a concept emerges from its relation with our body and its environment" (Yalvaç et al., 2011). Based on ECT, human experiences from the first years of life have been shaped through various sensory channels (Smith \& Gasser, 2005). These experiences also create perceptions about the concepts around a person. A movement has an important role in the acquisition of such perception. This forms the mental images of a person (Beilock \& Holt, 2007; Hostetter \& Alibali, 2008; Shapiro, 2011). The gestures, on the other hand, refer to a way to transfer a person's concepts in his/her mind to the outside world (Hostetter \& Alibali, 2008).

The gestures have been used in cognitive processes such as information packaging, lexical access (LA) and the TOT state. In these processes, the gestures play an important role in activating the visual images in the mind (Bavelas et al., 2008; Hadar \& Butterworth, 1997). Many researchers have reported that participants exhibit more symbolic gestures during face-to-face dialogues. However, participants also use more gestures when they are not in face-to-face dialogue, and they use more gestures especially in conveying difficult information (Alibali et al., 2001; Bavelas et al., 2008; Hostetter et al., 2007; Kita \& Davies, 2009; Melinger \& Kita, 2007; Mol \& Kita, 2012). The prohibition of gestures also affects the speech and information packaging process (Morsella \& Krauss, 2004; Raucher, 1992). On the other hand, Hostetter et al. (2007) address that it is not possible to prevent a person's movements completely even under lab conditions, and people can exhibit head, neck and leg movements other than hand movements similar to gestures, which in turn may facilitate cognitive processes. In summary, it is reported that prohibiting gestures may cause difficulties in information packaging and in LA process.

Considering that the gestures refer to motor movements used in the transfer of mental images, one may think that various experiences based on visual perception constitute an important component of creating mental images. One may also argue that visual impairments can affect gesture acquisition and use. Researchers who discuss the importance of visual perception such as social learning, watching and imitating a model argues that visual impairments may naturally lead to some limitations in the use of gestures (Frame, 2000; Sharkey et al., 2000). On the other hand, the researchers address that the only factor in the acquisition of the gestures is not the visual perception and discuss that the gestures are the natural processes of speech (Iverson \& Goldin-Meadow, 1997; 1998; Iverson et al., 2000). As a matter of fact, some studies report that individuals with visual impairments who cannot benefit from visual perception sufficiently benefit more from other sensory channels such as auditory and tactile perception ones (Cattaneo et al., 2008). Furthermore, visual perception does not constitute the only component of mental image creation. Previous studies report that individuals with visual impairments use different sensory channels within the processes of reasoning and inference, and they can achieve similar results compared to sighted individuals (Eardley \& Pring, 2014; Knauff \& May, 2006; Noordzij et al., 2007). 
Following the overview of previous studies, the main purpose of this study was to compare the effects of gestures on the lexical access of adults with visual impairments and sighted adults. The research questions were in the following:

1. Do the gesture use frequency scores in the symbolic gestures, beat gestures, self-adaptor gestures and the total frequency scores of all the gestures differ between participants with VI and sighted participants under gesture-free condition in the LA process?

2. Do the frequency scores of correct responses differ between participants with VI and sighted participants at the end of the LA process under the gesture-free and gesture-restricted conditions?

3. Do the frequency scores of correct responses differ within the groups for participants with VI and sighted participants under gesture-free and gesture-restricted conditions at the end of the LA process?

\section{Method}

\section{Research Design}

A $2 \times 2$ repeated measures design was used in the study. The independent variables were the use (gesturefree) and the gesture-restricted (no use of gestures). The dependent variables were the frequency of gesture use in symbolic gestures, beat gestures, self-adaptor gestures, and the total use of all these gestures as well as the frequency of correct responses at the end of LA.

\section{Participants}

20 adults with VI and 20 sighted adults participated in the study. While the mean age of the sighted participants was 26.30, the mean age of the participants with VI was 26.45. Both groups included 6 female and 14 male participants. There were 13 university students, 1 university graduate and 1 master's degree in both participant groups. Verbal Fluency (VF) Test (Lezak et al., 2012; Troyer, 2000; Troyer et al., 1997) was used to measure the verbal performances of the participants. VF Test consists of fonetic and categoric fluency subtests. In the fonetic fluency subtest, the participants were requested to produce words that start with the letters $\mathrm{K}, \mathrm{M}, \mathrm{T}$, and produce animal names in the categorical fluency subtest. In the phonetic fluency scores $(U=177 p=.05>.05)$ and in the categorical fluency scores no significant differences were found between the sighted participants and the participants with VI $(U=14, p=.10>.05)$.

\section{Study Materials}

At the first stage of the data collection, a Participant Information Form was developed to identify the participants, to collect their demographic information and to match the groups. The form was filled by the participants. Two groups of target word lists consisting of 30 words in each list were prepared by the researchers.

\section{Target Word Lists}

Two groups of target word lists consisting of a total of 60 words were used to determine the effects of gesture use in adults with VI and sighted adults throughout the LA process. Three steps were followed in the selection of word groups. These included creating a word pool, identifying the possible target word list, and finalizing the target word groups.

In the first step, a pool of 250 words that evoked some concrete images in the minds of the people and was therefore suitable to use gestures was created (Beattie \& Coughlan, 1999; Frick-Horbury \& Guttentag, 1998; Pine et al., 2007; Rubin \& Friendly, 1986). In the second step, among the words in the pool those which had a frequency of use that was more than 3 per million in daily life were discarded. At the end of this elimination, 110 words remained in the pool. Dictionary meanings of the words were found. The list was presented to the opinions of three different field experts on gestures. A pilot study was conducted: 88 words which were agreed by the all experts were presented to two adults with VI and two sighted adults. As a result, the words with complex definitions that led to confusion with another word were removed from the list. Afterwards, a total of 60 words remained in terms of the frequency: They were divided into two target word lists involving 30 words in each list. 


\section{Procedure}

Initially, ethical permissions were obtained from Gazi University (protocol no. E. 70204). The study lab was a special room designed for experimental studies in a university-based research center and was free of external noise. During the implementation, the first researcher and each participant were present in the room. Two chairs, a video camera and a digital stopwatch were placed in the room. Following the informed consent of the participants, the participant responses were video recorded.

During the implementation, the meaning of the words in the target word lists was presented to each participant in two different conditions (gesture-free and gesture-restricted). In order to control a possible order effect, the word groups, the order of the words and the experimental conditions were presented to each participant in a random order. Before the experimental procedure, the participant was told that "In our study, we have a list of 2 different target words consisting of 30 words in each group. I am going to read you the dictionary meaning of a word from this list of the target words and ask you to guess the word following its definition. You will have 45 seconds to guess the word. After I have read the meaning of the word, please tell your response if you know the word. If you think you don't know the word, you can think until the time is up and then make your guess." In order for the participant to understand the process more easily, sample attempts were implemented with two words not placed in the lists. The study was conducted following these trials. The gesture-free and gesture-restricted conditions were implemented with all participants.

\section{Gesture-Free Condition}

In this condition, the participant was allowed to move his/her hands freely. The meaning of the word in the list was read. The prediction time was measured using the stopwatch. If the participant gave the correct response following the given definition, the researcher told the participant: "Now we move on to the other word." The meaning of a new word was read to the participant and the time was restarted. If the participant gave an answer and then changed his/her answer immediately, the participant was asked to tell his/ her answer clearly. When the participant said "I don't know", it was waited until the end of 45 seconds. Then, the implementation with the new word was initiated. When the participant's word prediction time expired (45 seconds in each word), s/he was told that the time had expired and the meaning of the new word was read. After the word list was finished, the participant was told that this step was completed.

\section{Gesture-Restricted Condition}

Under gesture-restricted condition, the participant was given the following instruction: "Place your right hand under your right leg and left hand under your left leg and do not move your hands" without using their gestures. The meaning of each word in the list was read to the participant. The prediction time was measured via the stopwatch. If the participant gave the correct response after the definition, the researcher told: "Now we move on to the other word." The meaning of a new word was read to the participant and the time was restarted. If the participant gave an answer and then changed his/her answer immediately, the participant was asked to tell his/her answer clearly. When the participant said "I don't know", the researcher waited until the end of 45 seconds and the process with a new word was initiated. When the participant's prediction time expired, s/he was told that the time expired and the meaning of the new word was read. After the word list was finished, the participant was told that this step was over.

\section{Coding, Scoring and Data Analysis \\ Gesture Codes}

In the coding procedure, the gestures of each participant were coded in three different categories: Symbolic gestures, beat gestures, and self-adaptor gestures. In each category, the frequency scores of gesture use in two groups of participants (adults with VI and sighted adults) were obtained. The definitions of gesture categories were presented below:

Symbolic Gestures. Those involving semantic meaning (Beattie \& Coughlan, 1999; Frick, 1991; McNeill, 1992) and describing the shape of an object, how an object was used, or its function, its movement, or its location were coded as symbolic gestures. 
Beat Gestures. Rhythmic and repetitive simple motor movements (Beattie \& Coughlan, 1999; Frick, 1991) without semantic meanings were coded as beat gestures.

Self-Adaptor Gestures. The hand movements (Beattie \& Coughlan, 1999) which the participant used for self-adaptation purposes were coded as self-adaptor gestures.

\section{Coding and Scoring the Correct Response at the End of the LA Process}

After the researcher read the dictionary meaning of each word in the lists, the word guessing procedure of each participant was initiated. In the case of the correct guess, the LA was coded successfully and 1 point was given. If the participant guessed the word wrong, it was stated that s/he did not know the word or could not make any guesses, the LA was coded unsuccessfully, and 0 point was given. If participant made a guess in the LA process, immediately changed his/her guess, and if his/her last answer was correct, the participant was given 1 point. If participant made a guess in the LA process, immediately changed his/her guess, and if his/her last answer was wrong, the participant was given 0 point. At the end of the LA process, the scores of the frequency of the right answers were calculated by counting the right answers given by the participant.

\section{Inter-Observer Reliability and Implementation Fidelity}

Regarding the inter-observer reliability and measurement fidelity of the study, a second observer randomly selected, watched and coded the videos ( $n=12,6$ adults with VI and 6 sighted adults). The inter-observer reliability rate was calculated as $94 \%$ whereas the implementation fidelity of the study was calculated as $97 \%$.

\section{Data Analysis}

A Shapiro-Wilk test was used to assess normal distribution. The homogeneity of variances of the data was tested with the Levene Homogeneity test. Since the data was not normally distributed possibly due to the limited number of participants the Mann-Whitney U test was used for between-groups comparisons. The Wilcoxon Signed Ranks test was used for within-group comparisons. When interpreting the effect sizes, $\geq 0.10$ was accepted as small effect, $\geq 0.30$ as medium effect, $\geq 0.50$ as high effect, and above $\geq 0.70$ as very high effect sizes (Cohen, 1988, Field et al., 2012).

\section{Findings}

\section{Comparisons of the Frequency Scores of the Gestures Used by Adults with VI and Sighted Adults in the} Gesture-Free Condition

In the gesture-free condition, the difference between the frequency scores of symbolic, beat, self-adaptor gestures, and total gestures were compared between adults with VI and sighted adults. There were no significant differences between sighted participants and the participants with VI in the use of symbolic gestures $(U=131.00$ $p=.05>.05)$ and in self adaptor gestures $(U=139, p=.09>.05)$. However, a significant difference was found between sighted participants and participants with VI $(U=112.00, p=.01<.05)$ and the effect size of this significant difference was found to be at a moderate level with $r=0.38(r \geq .30)$ in the use of beat gestures.

\section{Comparison of the Frequency Scores of the Right Answers in the Gesture-Free and Gesture-Restricted Conditions}

The frequency scores of the right answers at the end of the LA process under gesture-free and gesturerestricted conditions between the participants with VI and sighted participants were compared. In the gesturerestricted condition, a significant difference was found between the frequency scores of the right answers between the sighted participants at the end of the LA process and the frequency scores of the right answers of participants with VI at the end of the LA process $(U=73.50, p=.001<.05)$. The effect size of the difference was observed to be at a high level with $\mathrm{r}=0.54(r \geq .50)$. In gesture-free condition, there were no significant differences between the two groups $(U=112.00, p=.11>.05)$. 


\section{Within-Group Comparisons of the Frequency Scores of the Correct Answers in Gesture-Free and Gesture- Restricted Conditions}

No significant differences were found between the frequency scores of the right answers at the end of the LA process under gesture-free condition. However, under gesture-restricted condition, a significant difference was found between the sighted participants and participants with VI $(Z=-2.60, p=.009<.05)$.

\section{Discussion and Conclusion}

In the study, it was first examined whether there was a significant difference between the frequency levels of symbolic gestures, beat gestures, and self-adaptor gestures along with total gesture use during the LA process under gesture-free and gesture-restricted conditions between the adults with VI and sighted adults. No significant differences were found between the two groups regarding the frequency of the use of symbolic and self-adaptor gestures in gesture-free condition. However, the participants with VI used significantly fewer beat gestures than sighted participants.

The participants with VI used significantly fewer beat gestures compared to sighted participants in gesture-free condition. This might indicate that beat gestures may be obtained mainly through observation. Previous studies show that the gestures used by individuals with VI are similar to their sighted peers (Iverson \& Goldin-Meadow, 1997; 1998; Iverson et al., 2000). The results of this study between the groups in the use of symbolic gestures and self-adaptor gestures are similar to the literature. Some studies emphasize gesture acquisition can also develop with the help of tactile inputs in the absence of visual inputs. Some studies also suggest that visual impairments can be compensate through tactile inputs (Iverson \& Goldin-Meadow, 1997).

The second question of the study explored whether there was a significant difference between the participant groups in regard to the frequency scores of the right answers at the end of the LA process under gesturefree and gesture-restricted conditions. Under the first condition, there was no significant difference between the frequency of the right answers, but under the second condition, the scores of individuals with VI's correct answers decreased significantly compared to the scores of the sighted participants. Since the two groups showed similar success in achieving correct answers under gesture-free condition, these results may suggest that gesture use have similar effects among both groups. Overall, this finding may indicate that the gestures serve similar functions through the use of similar strategies both within participants with VI as well as the sighted ones.

The participants with VI who did not use gestures provided less number of correct responses compared to the sighted participants at the end of the LA process. The inhibition of the gestures may have prevented individuals with VI from activating their mental images in their minds and remembering information correctly. In addition, considering that individuals with VI utilize tactile inputs when creating images about concepts, one may think that blocking the use of their hands may actually mean blocking their crucial information channels as well. In addition, while the gesture use of participants with VI was free, they gave more correct answers at the end of LA process. These results indicate that the participants with VI are able to gather information more easily when gestures are free, and when their gestures are restricted, they produce less correct results. It has been well documented that the use of gestures in the sighted individuals facilitates the LA process via images in their minds, and the rate of the correct responses of participants whose gestures are blocked decreases at the end of the LA process (Frick, 1991; Frick-Horbury \& Guttentag, 2001; Hadar \& Butterworth, 1997; Hostetter et al., 2007; Krauss et al., 1996; Rauscher, 1992; Ravizza, 2003).

On the other hand, there were no significant differences between the frequency of the correct responses at the end of the LA under gesture-free and gesture-restricted conditions in the sighted participants. This result showed that these conditions did not have an effect on correct responses of the sighted adults at the end of LA. Previous studies showed that gesture use had an effect on the correct responses of the participants at the end of LA (Frick, 1991; Hostetter et al., 2007; Krauss et al., 1996; Rauscher, 1992; Ravizza, 2003). However, when the gestures of the participants were blocked, they still continued to exhibit some movements similar to gestures such as moving their heads, their feet and their shoulders, which may in turn have affected the study results (Hostetter et al., 2007). In this study, when the sighted participants' gesture use was prohibited, they used gestures similar to symbolic gestures with their feet and heads. In any case, similar to the hand movements of the participants, these head, feet and shoulder movements could have helped the participants make the correct prediction. However, the 
participants with VI under gesture-restricted condition did not use these unintentional body movements frequently and they were less successful at the end of the LA process.

It is thought that the only input channel in the acquisition of gestures cannot only be the visual perception. Clearly, the gestures used in the beat function can be obtained through different learning mechanisms. On the other hand, the results regarding the correct response frequency scores of gesture use at the end of LA did not show any group differences. These findings indicate that the individuals with VI use gestures as an aid and reminder similar to the sighted individuals. Nevertheless, the frequency scores of the correct responses of the sighted participants did not differ under gesture-restricted and gesture-free conditions at the end of LA. On the other hand, it is thought that the individuals with VI may have utilized more tactile input in the process of acquiring knowledge and various concepts.

Considering that the perceptions about the concepts proposed by ECT are formed by using multiple sensory channels together and sometimes interchangeably (Beilock \& Holt, 2007; Hostetter \& Alibali, 2008; Lindbolm, 2015; Shapiro, 2011), the importance of the learning experiences in the early years become evident. The individuals who are provided with different learning opportunities and presented with experiences of learning by doing during early childhood period can be accepted as crucial implementations in the formation of mental images and transferring these images to the outside world. Indeed, the fact that both groups in the study used symbolic gestures with similar frequency may indicate that they used gestures for similar cognitive purposes. The fact that individuals with VI used symbolic gestures in the same levels with the sighted participants may also suggest that different sensorimotor experiences provide similar gesture outputs in individuals with VI.

In future studies, measuring the time in retrieving correct responses can provide additional information about the role of gestures on the cognitive speed of the participants and the difficulties encountered during the LA process. In order to understand the effects of the cognitive processes and gesture use patterns, future studies can also include participants who have lower educational levels. In addition, in order to understand the deterioration that may occur in the use of gestures individuals who lose their vision while they already have functional vision can also be examined as a sample group. Considering that the gesture acquisition is affected by different sensorymotor experiences and other learning experiences during the first years of life, the individuals with VI who lose their vision at birth or during early childhood can be examined to add further understanding of the role of vision in gesture development and functions in the LA process.

\section{Author's Contributions}

The authors collaboratively performed the tasks of determining the subject of the manuscript, research design, data collection, data analysis and reporting of the study. 